University of Louisville

ThinkIR: The University of Louisville's Institutional Repository

Electronic Theses and Dissertations

$12-2013$

\title{
A non-invasive method for measuring blood flow rate in superficial veins from a single thermal image.
}

Heba E. Farag

University of Louisville

Follow this and additional works at: https://ir.library.louisville.edu/etd

\section{Recommended Citation}

Farag, Heba E., "A non-invasive method for measuring blood flow rate in superficial veins from a single thermal image." (2013). Electronic Theses and Dissertations. Paper 426.

https://doi.org/10.18297/etd/426

This Master's Thesis is brought to you for free and open access by ThinkIR: The University of Louisville's Institutional Repository. It has been accepted for inclusion in Electronic Theses and Dissertations by an authorized administrator of ThinkIR: The University of Louisville's Institutional Repository. This title appears here courtesy of the author, who has retained all other copyrights. For more information, please contact thinkir@louisville.edu. 


\title{
A NON-INVASIVE METHOD FOR MEASURING BLOOD FLOW RATE IN SUPERFICIAL VEINS FROM A SINGLE THERMAL IMAGE
}

\author{
By \\ Heba E. Farag \\ B.S. ECE, Higher Technological Institute, 2011 \\ A Thesis \\ Submitted to J. B. Speed School of Engineering \\ University of Louisville \\ in Partial Fulfillment of the Requirements \\ for the Degree of \\ Master of Science \\ Department of Electrical and Computer Engineering \\ University of Louisville \\ Louisville, Kentucky
}

December 2013 



\title{
A NON-INVASIVE METHOD FOR MEASURING BLOOD FLOW RATE IN SUPERFICIAL VEINS FROM A SINGLE THERMAL IMAGE
}

\author{
By \\ Heba E. Farag \\ B.S. ECE, Higher Technological Institute, 2011 \\ A Thesis Approved on \\ November 18, 2013 \\ By The Following Thesis Committee Members: \\ Dr. Aly A. Farag, Thesis Director \\ Dr. Ayman EL-Baz \\ Dr. Shamus McNamara
}




\section{DEDICATION}

To my parents and my brothers, of whom I would not be here today

without their continuous love, support, and always encouraging me to be in a better place. 


\section{ACKNOWLEDGEMENTS}

Continuing to be here till the end with all the difficulties I had is the result of contribution from my family and my friends here or in my country. I would like to thank all the mentors that have given so during my college career, namely the faculty and staff at Speed School. Special thanks to my friend Marwa who treated me as her sister. She kept supporting me to learn and always kept taking care of me. Also, I would like to give special thanks to Ali Mahmoud and Ahmed Al Barkoky who helped me a lot in this work and without them, I wouldn't do anything. I offer special gratitude toward my Thesis Director, Dr. Aly A. Farag, and Thesis Committee, Dr. Ayman El Baz, and Dr. Shamus McNamara. I would like to extend special thanks to all my colleagues in the CVIP lab for their technical support over the past year. 


\title{
ABSTRACT
}

\section{A NON-INVASIVE METHOD FOR MEASURING BLOOD FLOW RATE IN SUPERFICIAL VEINS FROM A SINGLE THERMAL IMAGE}

\author{
By \\ Heba E. Farag \\ November $18^{\text {th }}, 2013$
}

\begin{abstract}
Computer vision is a field that includes methods for processing, analyzing, acquiring and understanding images to produce numerical or symbolic information to develop methodologies and solutions for many problems in many fields. Here the concept of computer vision is being used for understanding certain human physiology and behaviors using thermal imaging alone or in conjunction with other imaging modalities. The applications of this work span a wide range of studies in human-machine interfacing vis-à-vis feedback controls that can be used to remotely determine whether a patient is in need of medical assistance or to help integrate young children with learning challenges into a public classroom setting that can require monitoring vital signs and physiological cues without the need for contact-based sensors such as electrocardiogram (ECG) or electroencephalogram (EEG), which limit a subject's physical capabilities during operational scenarios.
\end{abstract}


In this thesis, a general framework is proposed to find an easy way to measure the blood flow using thermal camera to help detecting cots and vascular diseases (Venous disease, Arterial disease).

In this thesis, a general framework is proposed to use a thermal image based measurement technique for the volumetric flow rate of a liquid inside a thin tube. This technique makes use of the convection heat transfer dependency between the flow rate and the temperature of the flowing liquid along the tube. The proposed method can be applied to diagnose superficial venous disease non-invasively by measuring the volumetric blood flow rate from a FLIR LWIR single thermal image (Mahmoud et al., $13)$. 


\section{TABLE OF CONTENTS}

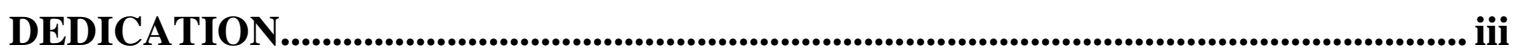
ACKNOWLEDGEMENTS ......................................................................................... iiv

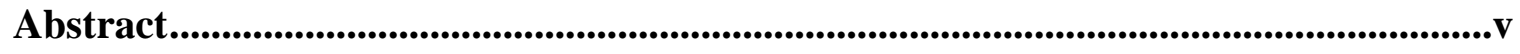

List of figures................................................................................................................................................ ix

Chapter 1. Introduction ..................................................................................................................1

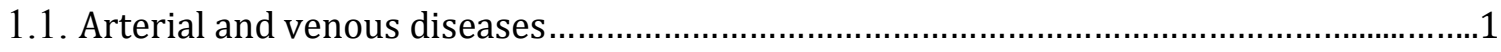

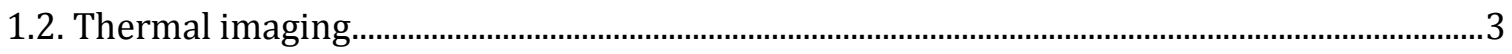

Chapter 2. Thermal Imaging ...........................................................................................................6

2.1. Thermal Radiation and Image Formation......................................................................................... 6

2.1.1. Measuring Thermal Radiation.................................................................................

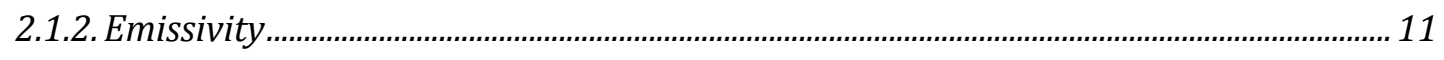

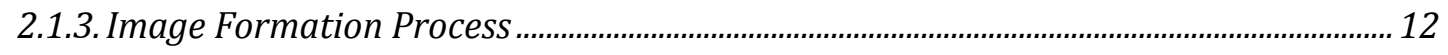

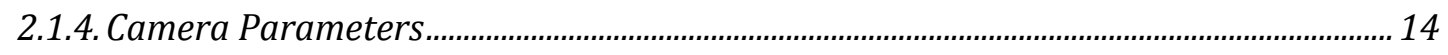

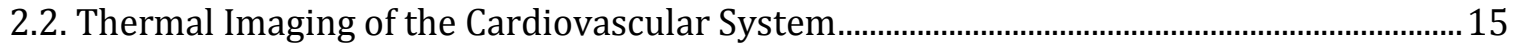

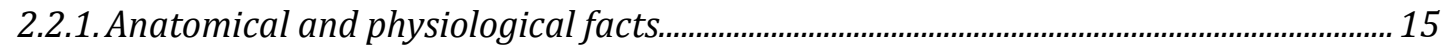

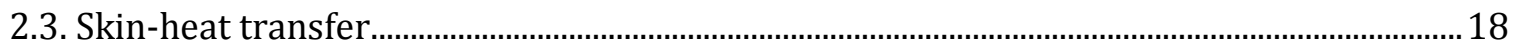

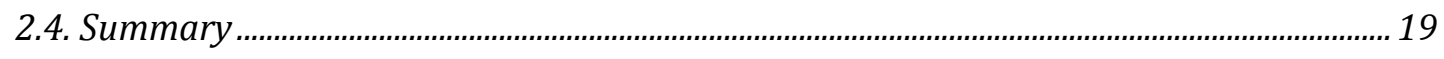

Chapter 3. fluid flow overview.......................................................................................................20

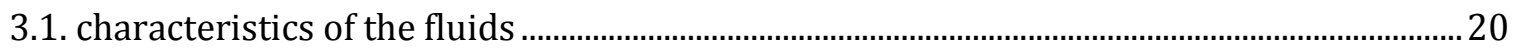

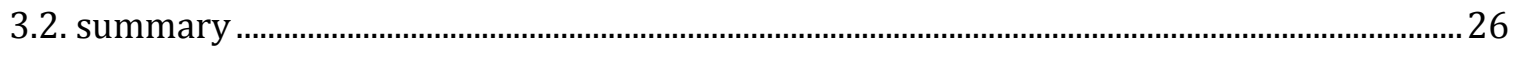

Chapter 4. measurement techniques for flow and volume of blood ................................27

4.1. measurement techniques of the blood ................................................................................2

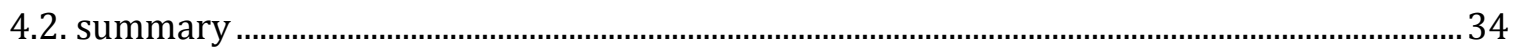


Chapter 5. A Non invasive methode for measuring blood flow rate in superficial veins from a single thermal image ..................................................................................................35

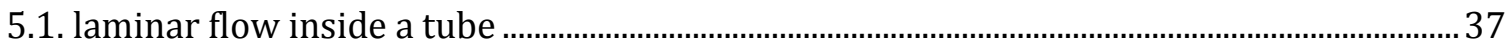

5.1.1 flow rate using convection heat transfer ........................................................................................ 37

5.1.2. pressure drop and power loss due to friction …………………........................................... 40

5.2. blood vessel convection heat transfer ........................................................................................... 43

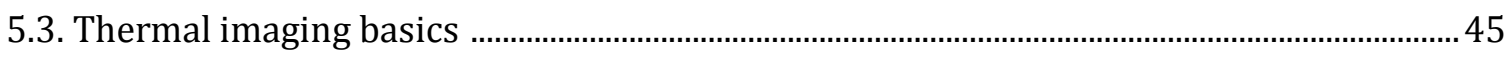

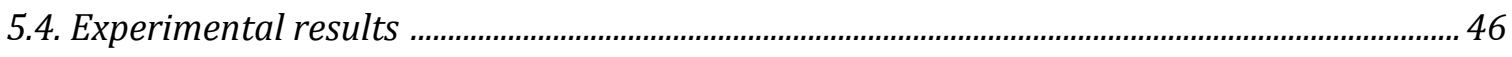

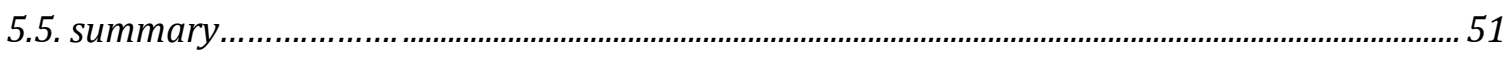

Chapter 6. CONCLUSION AND FUTURE WORK .........................................................52

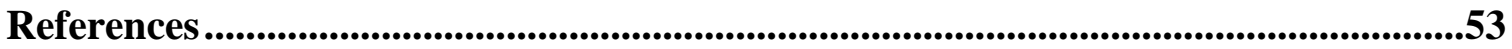

APPENDIX I. Mathematical Nomenclature .........................................................................62

APPENDIX II. Acronymns ..........................................................................................................63

CURRICULUM VITAE. ......................................................................................................65 


\section{LIST OF FIGURES}

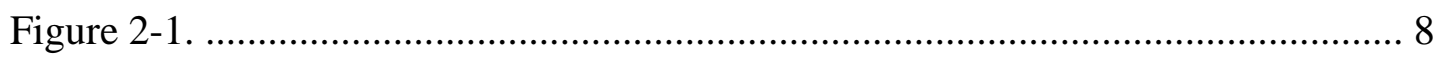

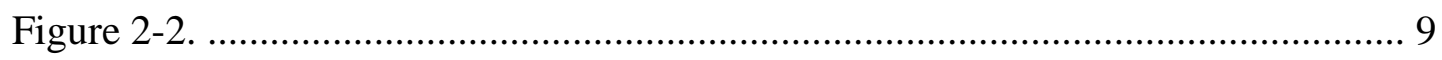

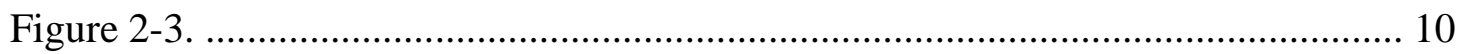

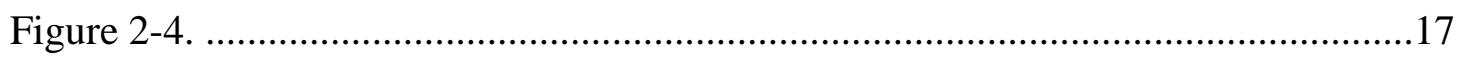

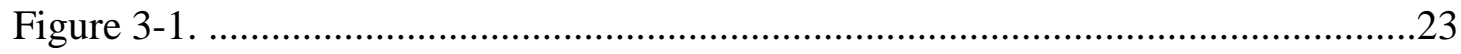

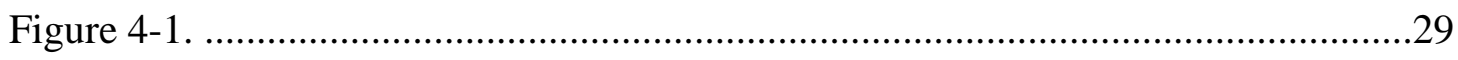

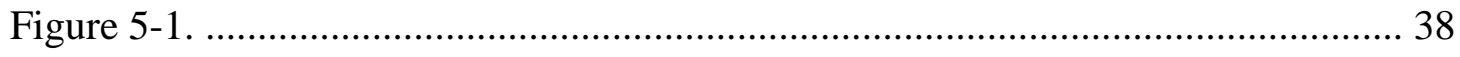

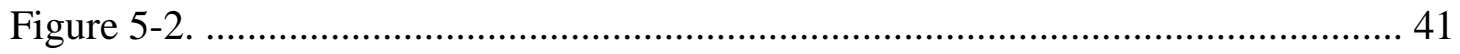

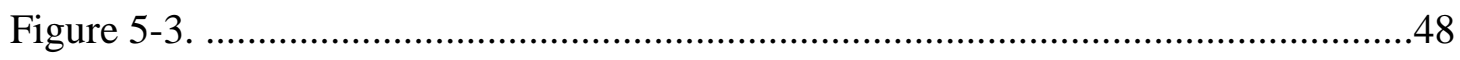

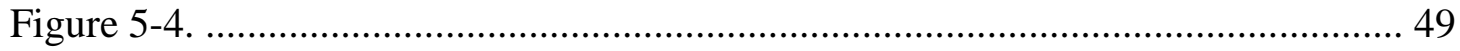

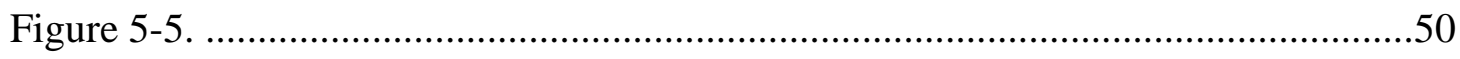

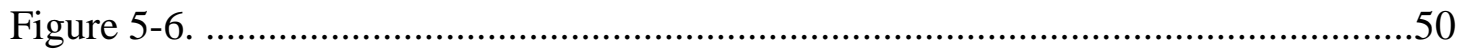




\section{INTRODUCTION}

\subsection{Arterial and venous diseases}

Venous disease refers to all conditions related to or caused by veins that become abnormal. Venous disease is quite common, about 15 percent of the adult population is affected. Mild venous disease is usually not a problem for patients but as it worsens, it become crippling chronic venous insufficiency. In normal circulation, arteries carry oxygen rich blood from the heart to all the organs of the body, and veins return the blood back to the heart. Veins have one-way valves along their length to keep the blood flowing to the heart. As muscles contrast, the blood is squeezed forward in the veins. When muscles relax, the valves shut to prevent blood from flowing backward. There are three types of veins in the body: superficial veins, communicating veins, and deep veins. For example superficial veins lie just under the skin and carry about 10 to 15 percent of the blood in the legs. Superficial veins drain into communicating veins, which drain into deep veins. Deep veins lie inside the muscles which are responsible for pumping the blood and carry around 85 to 90 percent of the blood back to the heart. If the vein walls become weak or damaged, or if the valves are stretched or injured, the system stops working normally and the blood begins to flow backward when the muscles relax. This creates unusually high pressure in the veins, resulting in even more stretching, twisting, and swelling of veins. The abnormal veins with their sluggish blood flow create disorders

known as venous disease. Later proposed method for measuring the blood flow in the superficial veins is being explained. Venous diseases include: 
Spider veins, Varicose veins, Leg Swelling and Leg Pain, Chronic venous insufficiency, Leg skin changes, Leg ulcers, Phlebitis, Vascular Malformations and Venous Malformations. Risk factors for venous disease include, Family history, Obesity, Pregnancy, Prolonged standing, Prior history of blood clot formation in the veins, Trauma, Illness, Surgery, Medications and Lifestyle.

One of the diseases of the veins is called phlebitis which means inflammation of the vein. It can affect the superficial vein or the deep veins. Thrombus (clots) is almost always associated with phlebitis. If the clot is in a vein, it is causes stretching and inflammation of the vein. If the clot is in one of the superficial veins, it is called superficial Thrombophlebitis.

Superficial Thrombophlebitis often develops in varicose vein where the blood flow has become sluggish. An ultrasound may be able to detect the clot in the vein. An idea of detecting the problem with the blood flow in the superficial vein using thermal camera is discussed later on the coming chapters.

Another type of the diseases that that occurs due to the blood flow problems is arterial disease; Peripheral artery disease which is also called peripheral vascular disease refers to the liquid deposition and the resulting inflammation in the endothelium of the arteries outside the heart; mainly the arteries supplying the lower extremities. It is a common circulatory problem in which narrowed arteries reduce blood flow to the limbs. In case that the peripheral arterial disease (PAD) happened, the extremities specially the legs not receive enough blood flow to keep up with demand. This causes symptoms, most notably leg pain when walking (intermittent claudication). 
Patients over the age of 70 , or patients over age 50 who have diabetes or a history of smoking, are at high risk for peripheral vascular disease (PVD) but probably not know it. Arterial disease and venous disease are so common these days, early detection for them helps more in recovering it. In 2000, one in 16 adults aged 40 years and older in the United States was found to suffer from peripheral arterial disease (PAD). The initiation and the progression of atherosclerosis in PAD involve multiple factors such as Platelet activation, thrombosis, endothelial dysfunction and vascular smooth muscle activation [Faxon, Fuster et al., 2004]. One of the problems of the Atherosclerotic plaque formation is narrowing of the vessel lumen and blocks the circulation to the leg, muscles and feet. Contrast angiography is considered one of the best ways to evaluate patients with PAD of lower limbs and also provides information about the arterial anatomy.

The most commonly employed techniques for the in vivo measurement of arterial blood flow to individual organs involve the use of flow probes or sensors. There are some common available systems for the measurement of in vivo blood flow which can be divided into two categories: ultrasonic and electromagnetic. Two types of ultrasonic probes are used. The first type of flow probe measures blood flow-mediated Doppler shifts (Doppler flowmetry) in a vessel. The second type of flow probe measures the transit time required by an emitted ultrasound wave to traverse the vessel. Measurement of blood flow in any vessel requires that the flow probe or sensor be highly accurate and exhibit signal linearity over the flow range in the vessel of interest. Moreover, additional desirable features include compact design, size, and weight. An additional important feature of flow probes is that they exhibit good biocompatibility, it is imperative for the sensor to behave in an inert manner towards the biological system. The purpose of 
measuring blood flow is to determine the amount of blood delivered to a given region per unit of time (milliliters per minute) and it is desirable to achieve this goal by noninvasive methodologies. This, however, is not always possible. An overview of some of the techniques available for the assessment of regional blood flow in the vascular system is being discussed later.

To early detect these kinds of diseases measurement of the blood flow rates needs to be made. Measuring the blood flow rate plays an important role in many medical applications among which is vascular disease diagnosis. Vascular disease is a disorder that occurs in the blood vessels which can lead to improper human blood circulation. Among vascular diseases are arterial disease that affects arteries which carry oxygen-rich blood from the heart to the body organs, and venous disease that affects veins which carry blood back from the organs to the heart to be purified. Regarding the veins, superficial veins which are located near the skin surface can have a clot on it. There are some different techniques to diagnose superficial venous disease and one of them is to diagnose it using a thermal image.

\subsection{Thermal imaging}

Thermal imaging offers an exciting means for imaging humans to extract vital signs in clinical conditions. One of the advantages to using thermal imaging is that subjects in the camera's field of view are invariant to light, as the subjects act as the light source. The radiated power per unit area (RPPA) can be calculated using Planck's blackbody radiation law, which also aids in determining the imaging spectrum to use. With current advances in focal plane array (FPA) size and the development of multi-band 
cameras, this field offers the potential for exciting possibilities in the future to diagnose vascular diseases with high efficiency.

Some thermal cameras are capable of detecting minute changes in the temperature on the surface area of the skin, resulting from the circulation of blood through the cardiovascular system. Cooling from the environment, metabolic processes, and the draining of venous pools create minor temperature variations on the skin of $200 \mathrm{mK}$. These variations are primarily due to blood perfusion resulting from the vasculature and not the bone or core, which remain at a relatively constant temperature [Love80].

A method for measuring the blood flow using the thermal camera is explained here through an experimental work. Understanding the anatomy of the body, the physics and the camera parameters is crucial to design the experiments to complete this work.

Beyond spatial resolution and focal length, there are certain parameters that are of interest to the user of a thermal camera. These parameters are the detectivity, contrast, thermal sensitivity, the noise equivalent temperature difference, and the minimum resolvable temperature difference.

During diastole, the heart expands and the blood exits the capillary bed via the veins to the venous return channels. As a result, the blood temperature in a vein represents the average temperature of the tissues drained by that vein. The blood is reheated as the process repeats. When the body attempts to maintain homeostasis, heat variations resulting from the underlying vasculature are conducted through soft tissues and measurable by an IR camera [Campbel197, Diastole10, Love80, and Systole10]. 


\section{THERMAL IMAGING}

\subsection{THERMAL RADIATION AND IMAGE FORMATION}

Transfer of Thermal energy happens through the means of conduction, convection, and radiation. A model of radiation is illustrated in $(2.1)$. The rate $\left(\dot{Q}_{e}\right)$ in which an object emits thermal energy depends on the body's surface area (A), emissivity $(\varepsilon)$, and the body's $\left(T_{b o d y}\right)$ temperature in Kelvin. Here, $\sigma$ is the Stefan-Boltzmann constant which equals $\sigma=5.6703 \times 10^{-8}$. The emissivity of an object's surface depends on an object's surface composition and temperature and it has a domain of $[0,1] \in R$. As a result, the power per unit area that radiated by a blackbody depends only on the object's temperature and not on any other characteristic, such as material composition [Tipler03].

$$
\dot{Q}_{e}=\varepsilon \sigma A T_{b o d y}^{4}
$$

It is known that all real sources reflect, transmit, and absorb radiant energy at different wavelengths, which equals the total radiant incident to the body. This is illustrated in (2.2), where $\rho, \tau$, and $\alpha$ represent the object's reflectivity, transmissivity, and absorptivity, respectively; Kirchhoff's law states that emissivity and absorptivity are equivalent. Each of these three physical properties varies dependent on wavelength [Halliday01].

$$
\rho(\lambda)+\alpha(\lambda)+\tau(\lambda)=1
$$

A blackbody has a high emissivity because it is essentially an opaque object in the spectrum under consideration. Skin acts as a near-ideal blackbody, with an emissivity in 
the range of 0.91-0.98 depending on sex and measurement location [Steketee73]; ideal black bodies have emissivity $\varepsilon=1$ because it absorb all radiation incident on them. Similar to the rate of thermal energy emission, the blackbody radiation's spectral distribution depends only on the absolute temperature of the blackbody [Infratec09].

$$
\begin{gathered}
P(\lambda, T)=\frac{8 \pi h c}{\lambda^{5}} \frac{1}{e^{h c / \lambda k T}-1}\left[\text { Watts } / \mathrm{m}^{2}\right] \\
\lambda_{m} T=[\mathrm{mk}] 2.898 \times 10^{-3}
\end{gathered}
$$

Planck's blackbody radiation law is known as the amplitude of the energy density spectral distribution function, it is used to find spectral regions where living humans emit the highest thermal energy. Wien's Law (2.4) is used to determine the location of the maximum amplitude of Planck's Law for a given temperature/wavelength pair. Using these equations as illustrated in the bottom of Figure 2.4, one can easily determine the best wavelength to monitor human thermal radiation is between $9-10 \mu \mathrm{m}$, meaning that the Long Wave IR band is the most suitable for thermal imaging of the face.

The maximum amplitude for the energy density spectral distribution function in (2.3) contains the spectral regions where living humans emit the highest thermal energy. Planck's and Wien's Laws clearly show the best wavelength to monitor human thermal radiation is between 9-10 $\mu \mathrm{m}$ under non-life threatening conditions.

\subsubsection{Measurement of thermal Radiation}

Unlike a traditional contact thermometer, which serves as the thermal sensor (to measure) and transducer (to quantify) the temperature, the radiant source itself acts as the sensor in a radiation thermometer's measurement. As a result, temperature is directly 
transduced into intensity of radiation. Thus, radiation measurements are directly thermodynamic, instead of analogs of thermodynamics [Sostmann95].

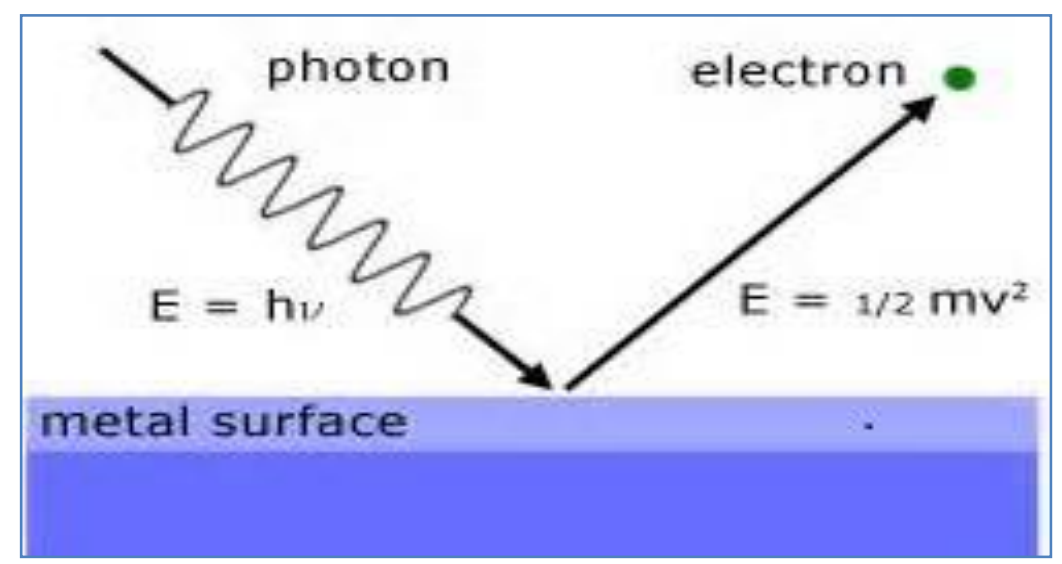

Figure 2.1: The photoelectric effect, where incident light waves impact a clean metallic surface, emits electrons

Thermal radiation is measured via the photoelectric effect, which is based on the principle that light incident on a clean metallic surface (acting as a cathode), emits electrons as in Figure 2.1, when the energy incident the surface exceeds a stopping potential, are explained below. If an anode containing a slit is placed opposite the cathode, electric current is created when a few electrons travel from the cathode to the anode and through the slit. The resulting current can be increased or decreased by changing the potential difference $(V)$ between the anode and cathode such that positive $V$ attracts electrons to the anode. If the intensity of light is too low to provide electrons with the necessary energy to escape from the metal, no electrons are emitted. This implies that the initial kinetic energy of the electrons $\left(1 / 2 m v^{2}\right)$ must be greater than $e|V|$ to travel to the anode, where $e$ is the charge of an electron. When $V$ is sufficiently large, all emitted electrons reach the anode, implying that the current reaches a maximum value, which is proportional to the light intensity. The potential $V_{0}$ is called the stopping 
potential and is related to the maximum kinetic energy of the emitted electrons by equation (2.5). If the potential difference $(V)$ is less than the negative of the stopping potential $\left(-V_{0}\right)$, no electrons reach the anode.

$$
e V_{0}=\left(\frac{1}{2} m v^{2}\right)_{\text {max }}=h f-\phi
$$

However, the maximum kinetic energy of the emitted electrons does not increase when the rate of energy falling on the cathode increases, which contradicts classical mechanics. Einstein later defines a work function, $(\boldsymbol{\phi})$ that is a characteristic of the metal defining the energy necessary to remove an electron from the metal's surface. Consequently, energy conservation requires that the maximum kinetic of the electrons leaving the metal's surface will be $(h f-\phi)$. Hence, the stopping potential, $V_{0}$, can be defined by (2.5); this equation is referred to as the photoelectric effect [Tippler03].

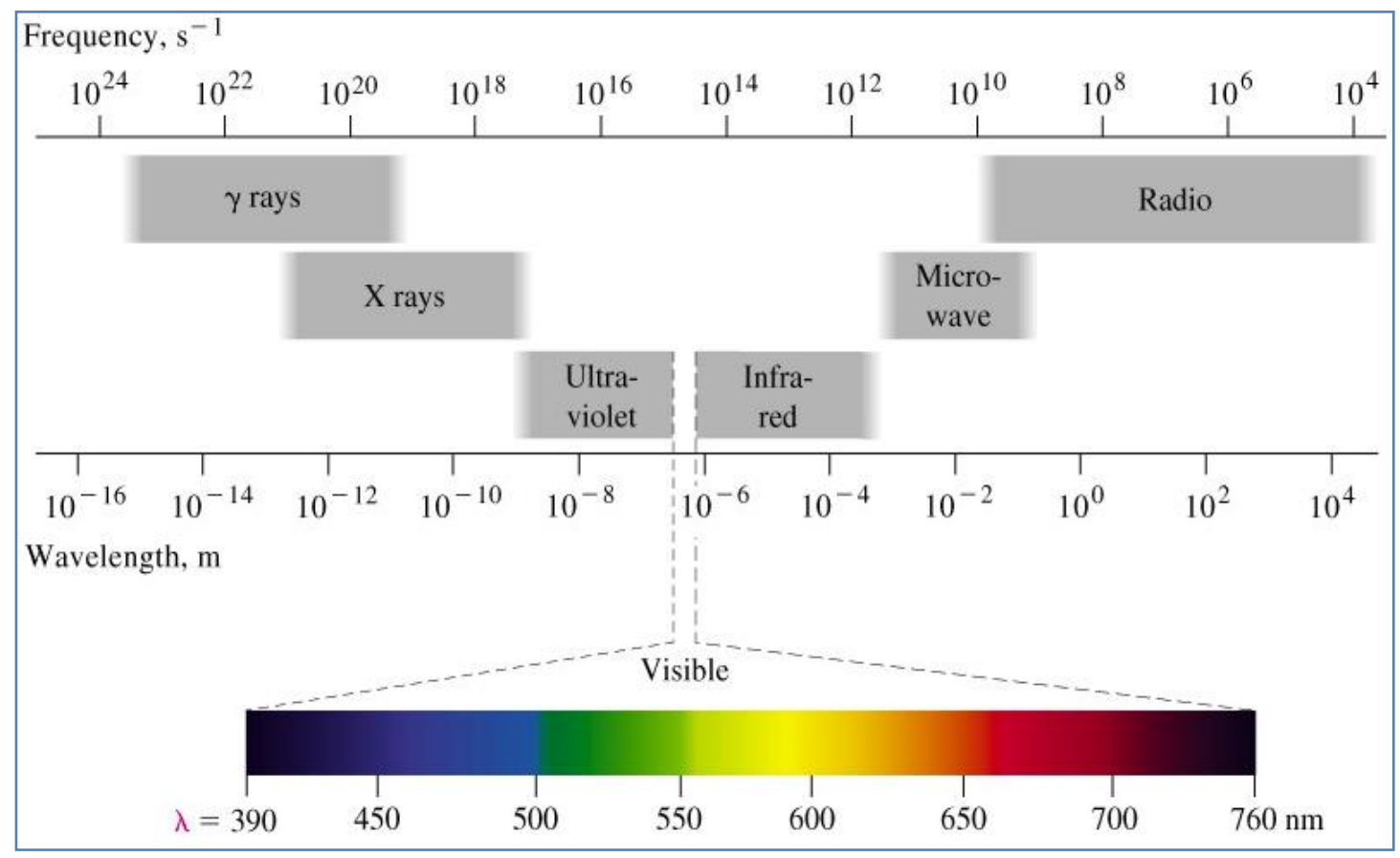

Figure 2.2: Wavelengths of thermal energy. 
The wavelength spectrum from $750 \mathrm{~nm}$ to $300 \mu \mathrm{m}$ is the IR spectrum which is illustrated in Figure 2.2, and is often divided into three regions: near infrared (780-2500 $\mathrm{nm})$, mid-infrared $(2.5-50 \mu \mathrm{m})$ and far infrared $(50-1000 \mu \mathrm{m})$. The discontinuities between the spectral regions are all unassigned because the components that comprise the atmosphere (water, carbon dioxide, oxygen, ozone, etc...) absorb all IR radiation at these wavelengths (see Figure 2.3). However, the mid-infrared region is of particular interest for thermal imaging applications and is divided into the short-wave, near-wave, midwave, long-wave and extreme IR sub-bands as defined at the top of Figure 2.2.

The wavelength at which molecules absorb IR radiation is dictated by the types of atoms composing a molecule, the molecular bond types, the locations of the atoms and molecular bonds, and their interactions within the molecule. When a molecule absorbs IR radiation, the molecule's energy increases and the radiation causes a change in the molecule's vibration or rotational motions. As a result, the net dipole moment of the molecule must change and the radiation energy must equal the difference between the molecule's allowed energy transitions. The Homonuclear diatoms: oxygen $\left(O_{2}\right)$, nitrogen $\left(\mathrm{N}_{2}\right)$, and hydrogen $\left(\mathrm{H}_{2}\right)$, are the only common molecules that do not absorb IR radiation, which means that their concentrations cannot be directly measured using IR spectroscopy [Barber05]. The radiation absorbed by the atmosphere is being illustrated in Figure 2.3. 


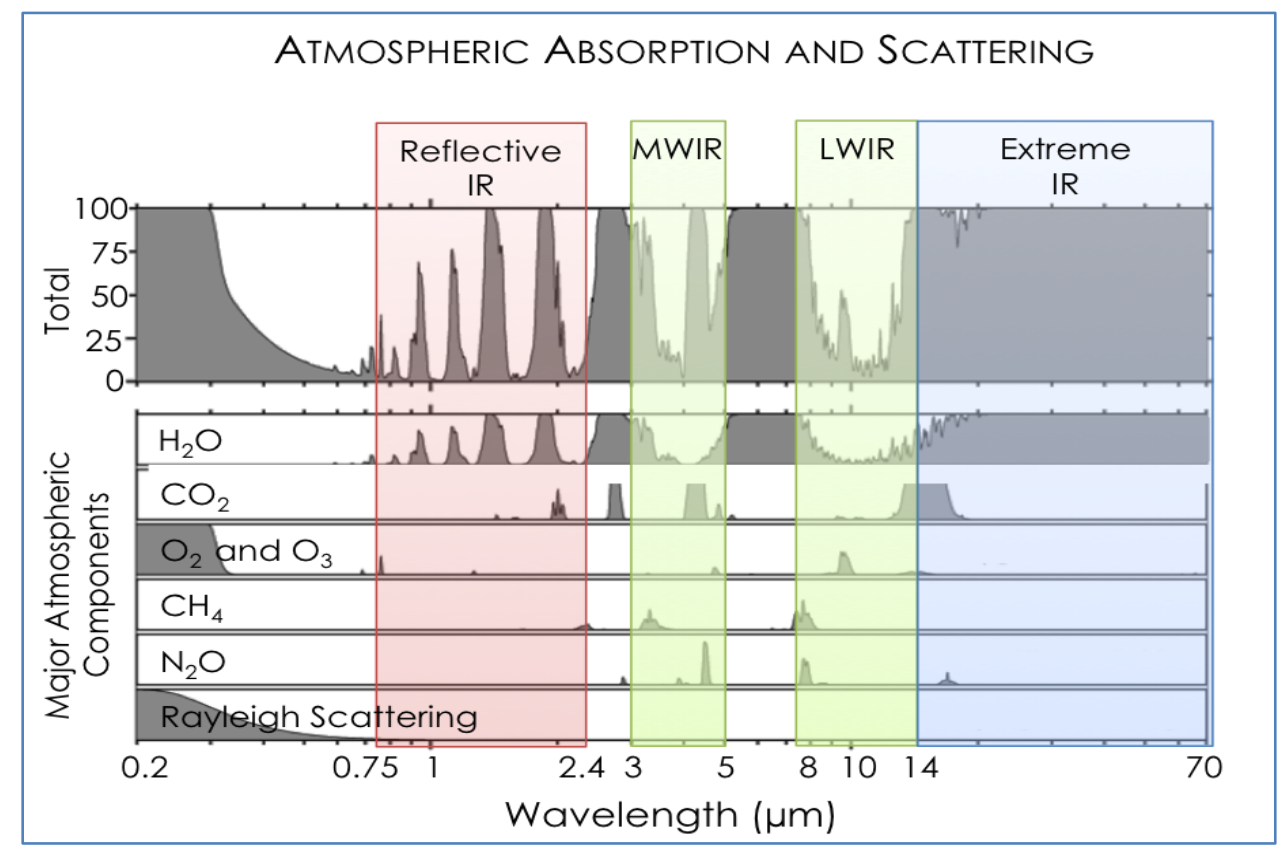

Figure 2.3: Total radiation absorbed (top) by the atmosphere with a breakdown of contributions from major atmospheric components (bottom).

\subsubsection{Emissivity}

The degree to which a body can emit thermal radiation is called emissivity. Depending on the wavelength ideal blackbodies have an emittance of unity. Conversely, real objects may show more or less dependence on wavelength. Material composition, oxide film on the surface, surface texture, angle incident the surface, temperature, and the degree of polarization are the parameters that affect emissivity. In the LWIR spectrum, many non-metallic materials show high and relatively constant emittance, regardless of the object's surface structure. Among these materials are coating paints, most mineral building materials, and human skin [Infratec09].

$$
\varepsilon_{\lambda}=\frac{q_{\lambda_{\text {surf }}}(T)}{q_{\lambda_{\text {body }}}(T)}
$$

The hemispherical emissivity of the surface $\left(\varepsilon_{\lambda}\right)$ is formulated in (2.6) as the ratio of the emissive heat flux for the surface $\left(q_{\lambda \text { suff }}\right)$ to the emissive heat flux for the blackbody 
$\left(q_{\lambda b b}\right)$ at the same temperature $(T)$ for a given wavelength [Wong04]. Planck's blackbody radiation law from (2.3) is used as the basis for determining the skin emissivity. For a blackbody at a known temperature $T$, at wavelengths $\lambda_{1}$ and $\lambda_{2}$, where $\lambda_{1}<\lambda_{2}$, the emitted radiation power per unit area (RPPA) be calculated by using (2.7). This calculation will also require the use of a radiometer that has been calibrated using two blackbody sources at different temperatures and has uniform sensitivity between $\lambda_{1}$ and $\lambda_{2}$. If the radiometer is directed toward human skin with emissivity $\varepsilon$ and temperature $T_{\text {skin }}$ in a room with ambient temperature $T_{a m b}$, then the RPPA at the temperature observed by the radiometer $\left(T_{r a d}\right)$ is given by (2.8). In this case, the reading from the radiometer and the RPPA for the skin serve as the values for the heat fluxes for the surface and blackbody in (2.45), respectively. When the blackbody is ideal, the effect of the ambient temperature is removed completely [Togawa89].

$$
\begin{gathered}
P(T)=\int_{\lambda_{1}}^{\lambda_{2}} P(\lambda, T)=\int_{\lambda_{1}}^{\lambda_{2}} \frac{8 \pi h c}{\lambda^{5}} \frac{1}{e^{h c / \lambda k T}-1} d \lambda \\
P\left(T_{\text {rad }}\right)=\varepsilon P\left(T_{\text {skin }}\right)+(1-\varepsilon) P\left(T_{\text {amb }}\right)
\end{gathered}
$$

It is necessary to remove the RPPA for the skin out of the equation. This is done physically by changing the ambient temperature instantly during the measurement process. If the RPPA is measured at wavelengths $\lambda_{1}$ and $\lambda_{2}$ at each ambient temperature, the system of equations in (2.9) can be solved in terms of the emissivity in (2.10). According to Wolff (2004), a conservative estimate for skin emissivity is 0.91 for the MWIR and 0.97 for the LWIR spectrums. Togawa found that the overall average for skin emissivity for LWIR imaging is $0.971 \pm 0.005 \%$ for males and females, and 0.969 $\pm 0.004 \%$ specifically for the forehead region. Thus, skin is a near-perfect radiator of 
thermal radiation when imaging in the LWIR spectrum and consequently, skin reflectance is inconsequential [Steketee73].

$$
\begin{gathered}
{\left[\begin{array}{l}
P\left(T_{r_{1}}\right)=\varepsilon P\left(T_{s_{1}}\right)+(1-\varepsilon) P\left(T_{a_{1}}\right) \\
P\left(T_{r_{2}}\right)=\varepsilon P\left(T_{s_{2}}\right)+(1-\varepsilon) P\left(T_{a_{2}}\right)
\end{array}\right.} \\
\varepsilon=1-\frac{P\left(T_{r_{2}}\right)-P\left(T_{r_{1}}\right)}{P\left(T_{a_{2}}\right)-P\left(T_{a_{1}}\right)}
\end{gathered}
$$

\subsubsection{Image Formation Process}

An image is formed basically using the same concept that the natural eye works with, where a light source is used to illuminate the 3D space which will be captured by the camera to form the captured image. Such image contains a set of pixels ordered in a rectangular grid, i.e. rows and columns, each pixel can be completely characterized by two aspects, its location and its intensity (gray level), where its location p (i.e. row and column indices) is directly related to the corresponding $3 \mathrm{D}$ world point $\mathrm{P}$, while its gray level is obtained by the camera which measures the degree of light reflectance at that $3 \mathrm{D}$ point. It is defined as a two-dimensional function, $\mathrm{I}(\mathrm{x}, \mathrm{y})$, where $\mathrm{x}$ and $\mathrm{y}$ are spatial coordinates and the amplitude of I at any pair of $\mathrm{x}$ - any $\mathrm{y}$-coordinates $(\mathrm{x}, \mathrm{y})$ is called the intensity or gray level of the image at that point. When the $\mathrm{x}$ - and $\mathrm{y}$-coordinates and the magnitude of $I$ are all finite and discrete values, the image is digital [Gonzalez02]. A thermal image, then, is a digital image whereby the gray levels represent a thermal quantity.

The process of creating a thermal image requires an object that emits thermal IR radiation which is placed in front of the IR camera lens. The IR lens focuses the radiation onto the focal plane array (FPA) of IR-sensitive detectors. The FPA uses the photoelectric effect to generate electrical signal and these signals are multiplexed and 
converted to a digital electrical signal, which is processed further to handle internal noise sources before being output to a video processor, this video processor converts the data into a 2D video frame, which is then captured via a frame-grabber in the computer. These images are returned as gray-levels and the intensity of the gray level is proportional to the temperature on the object's surface. This process is illustrated in Figure (2.4).

Some of the available thermal IR cameras are unit-color which means that their FPAs are sensitive to specific wavelength bands which depends on the composition of the detectors in the FPA. In this type of system, all photons incident to the FPA within the permissible spectrum contribute to the intensity level at that pixel location. A color scheme is sometimes mapped to the intensity levels during visualization for visual effect; this is called false coloring [Gunapala06, Rosalski06ab].

There are a large variety of thermal detectors and camera types that are suitable for different applications. The two main types of these detectors are thermal and quantum types. The primary difference between the two is that with thermal types, a material with a temperature-dependent parameter is heated due to the absorption of thermal energy. This is considered to be a two-step process because a material must be heated, then it is measured. With quantum types, the photons emitted from infrared radiation directly generate electrical current as a result of the photoelectric effect. Consequently, quantum detector types are more sensitive than thermal types, but the tradeoff is that quantum types require cryogenic cooling and are far more expensive [NDT08]. 


\subsubsection{Camera Parameters}

Camera parameter is one of the factors that have a great effect on the process of the thermal image formation. Beyond spatial resolution and focal length, there are certain parameters that are of interest to the user of a thermal camera. These parameters are the detectivity, contrast, thermal sensitivity, the noise equivalent temperature difference, and the minimum resolvable temperature difference.

The detectivity, $D^{*}$ (D-star), is the primary parameter of interest for detectors and is a measure of the signal to noise of a detector when one watt of IR radiation is input through an optical chopper. Formally, the detectivity is defined as the RMS signal-tonoise ratio (SNR) in a $1 \mathrm{~Hz}$ bandwidth per unit RMS incident radiation power per square root of detector area, and is expressed in units of $\mathrm{cmHz}^{1 / 2} \mathrm{~W}^{-1}$ or "Jones". This parameter varies inversely with the square root of the both the electrical bandwidth $(\Delta f)$ and the detector's sensitive area $\left(A_{d}\right)$. To simplify comparing between different detectors, this can happen using the Equation which is illustrated as (2.11), where $\Phi_{\varepsilon}$ is the spectral radiant incident power. The measurements for $\mathrm{D}^{*}$ are expressed in the format of $\mathrm{D}^{*}(\mathrm{~A}, \mathrm{~B}, \mathrm{C})$, where $\mathrm{A}$ is the temperature or wavelength of a radiation source, $\mathrm{B}$ is the chopping frequency and $\mathrm{C}$ is the bandwidth. Larger values of $\mathrm{D}^{*}$ indicate better detector elements [Hamamatsu04, Rosalski02].

$$
D^{*}=(S N R) \frac{(A \Delta f)^{1 / 2}}{\Phi_{\varepsilon}}
$$

Thermal images result from temperature differences in the objects in the camera's field of view as well as the differences in emissivity for those objects. The emissivity is the dominant factor that affects the thermal image contrast in case that the objects have 
the same temperature. The thermal contrast is defined as the ratio of the derivative of spectral photon incidence to the spectral photon incidence which is illustrated in equation (2.12). The contrast in the MWIR band at $300 \mathrm{~K}$ is $3.54 \%$ compared to $1.6 \%$ for the LWIR band at the same temperature [Rosalski06].

$$
C=\frac{\partial Q / \partial T}{Q}
$$

One of the factors that affect the thermal image quality is the Thermal sensitivity which essentially defines how well the camera will perform as the image contrast increases. Thermal sensitivity specifications typically range between $0.25^{\circ} \mathrm{C}(250 \mathrm{mK})$ and $0.05^{\circ} \mathrm{C}(50 \mathrm{mK})$. Thermal sensitivity varies proportionally with object temperature, meaning that in the signal to noise ratio (SNR) calculation, the noise level remains fixed. Consequently, hotter objects are better for imaging, but in room temperature applications, the thermal contrast is too low for this to be advantageous. However, the difference in sensitivity per gray-level value is more pronounced. The $f$-number of the camera lens (Focal ratio) affects the thermal sensitivity, where lower $f$-numbers increase thermal sensitivity [Electrophys08].

\subsection{THERMAL IMAGING OF THE CARDIOVASCULAR SYSTEM}

\subsubsection{ANATOMICAL AND PHYSIOLOGICAL FACTS}

During systole, the heart contracts and the blood heated in the core of the body is circulated through the various tissue layers via the arterial network and eventually reaches the skin via the capillaries. The heart consists of four chambers, namely the left and right atria and ventricles, which work in unison acting as a two-stroke pump to 
circulate the blood. As blood passes through the capillary bed, the temperatures between the skin and blood equilibrate. During diastole, the heart expands and the blood exits the capillary bed via the veins to the venous return channels. As a result, the blood temperature in a vein represents the average temperature of the tissues drained by that vein. The blood is reheated as the process repeats. When the body attempts to maintain homeostasis, heat variations resulting from the underlying vasculature are conducted through soft tissues and measurable by an IR camera [Campbel197, Diastole10, Love80, and Systole10]. Figure 2.4 illustrates these processes.

Some intrinsic physiological properties such as fatty deposits and hair can inhibit acquiring a strong signal. From a physiological standpoint, skin tissues and the fat of the subcutaneous tissues act as heat insulators, which effectively help maintain the body's normal core temperature. As the skin is exposed to the environment, it approaches the ambient temperature [Wu08]. While the typical anatomical structure involves a layer of fat between the muscle fascia and the skin, the thickness of this layer is extremely variable. Fatty tissue decreases the amplitude of the signal since contrast between the vasculature and surrounding tissue diminishes due to thermodynamic processes. Also, hair occludes the vasculature and blocks the signal acquisition completely [Atamaz06, Sun05]. Hence, for thermal measurements, a region of measurement should be selected in a physical region that is devoid of hair and has minimal fatty tissue deposits. 


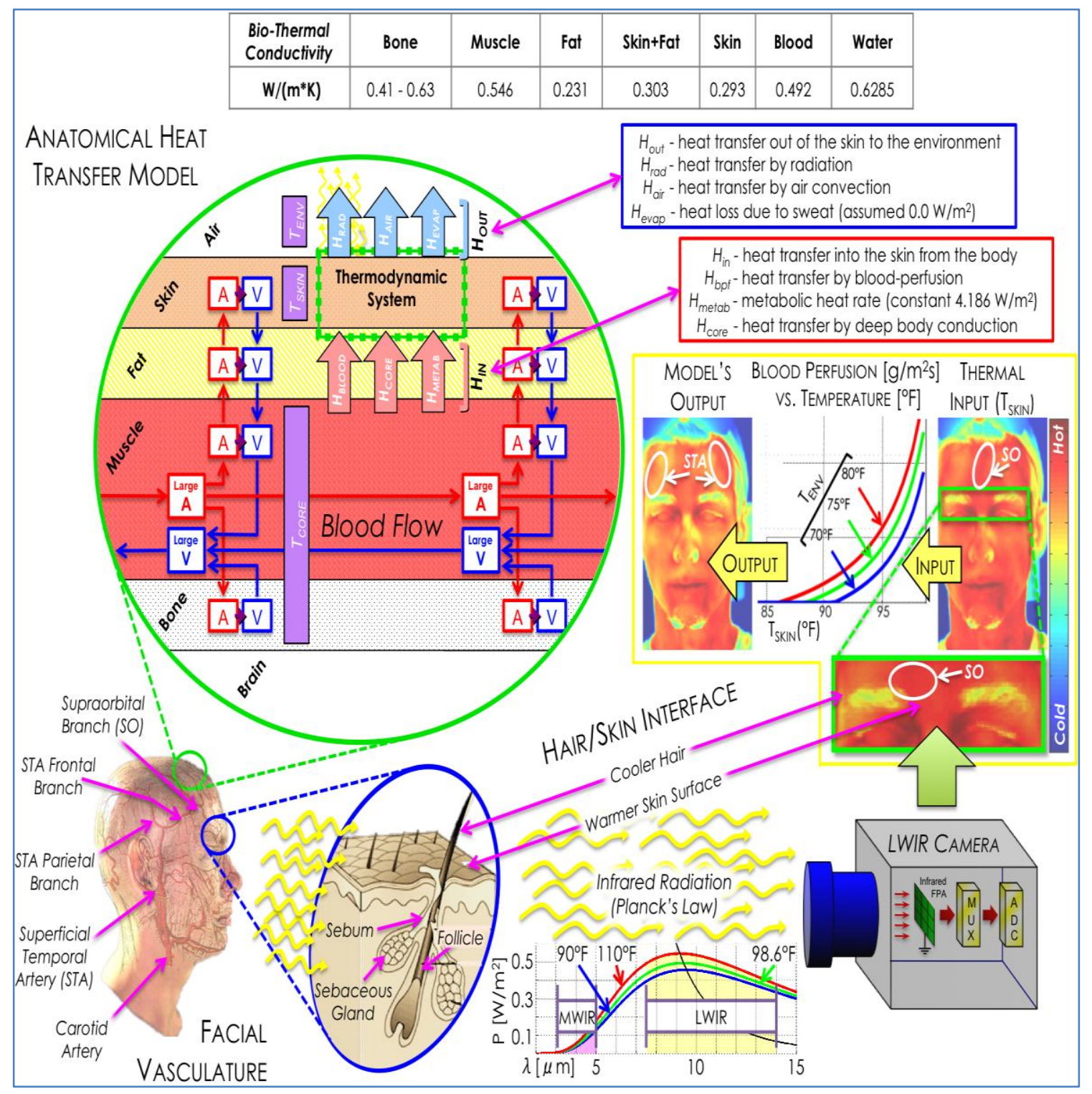

FIGURE 2.4: THERMAL FACIAL IMAGE FORMATION PROCESS WITH ASSOCIATED ANATOMICAL HEAT TRANSFER AND BLOOD PERFUSION MODELS. COURTESY, PHYSIOLOGY-AND WAVELET-BASED RECONSTRUCTION OF THE ARTERIAL PULSE WAVEFORMS FROM THERMAL VIDEO 


\subsection{Skin-heat transfer}

Skin-heat transfer (SHT) models account for the thermodynamic processes that contribute to the thermal quantity measured by the camera. These models vary depending on the complexity of the internal and environmental processes included, using the skin and its boundaries as the thermodynamic system. These models use heat fluxes originating from the blood, metabolism, and body's core as inputs to the system and heat fluxes due to thermal radiation, air, and sweat evaporation that emanate from the system; the net transfer in and out of the system must be equivalent as in (2.13). Wu et al. (2008) show that using some basic assumptions and practical imaging conditions (i.e. indoor imaging at rest with air-conditioning), that the amount of heat transferred via blood perfusion alone can be calculated as a function of the temperature read from the thermal camera. This important concept is the basis for determining the blood-pressure waveform from thermal imaging since the blood perfusion component is an integral part of the thermal video [Love80, Wu08].

$$
\begin{aligned}
& H_{\text {out }}=H_{\text {in }} \\
& H_{\text {out }}=H_{\text {rad }}+H_{\text {evap }}+H_{\text {air }} \\
& H_{\text {in }}=H_{\text {core }}+H_{\text {blood }}+H_{\text {metab }}
\end{aligned}
$$

Mathematically, the exchange of heat between the skin and the environment can be modeled using skin-heat transfer equations. These equations will change depending on the state of the subject. For example, a subject sitting at rest indoors will be affected less by evaporation due to sweat, than a subject that has just exercised. A few assumptions, based on the imaging environment and physiological state of the subject, are applied to simplify the model somewhat. In particular, this SHT model by Wu et al. (2008) is derived using three assumptions about the state of the subject and environment. 
Particularly, the ambient environment is assumed to be stable and lower than the body's temperature $\left(T_{\text {env }}<T_{\text {skin }}\right)$ and subjects are in a steady state $\left(T_{\text {core }}\right.$ constant $)$ without the need for biological temperature regulation such as sweating. Pathological conditions such as fever, headache, and inflammation, and psychological conditions such as anger or blush are not considered in their model. However, the work of [Love80, Pennes48], in which this model is derived from, can also be adapted to account for sweat and metabolic increases, which are of relevance for any work involving monitoring subjects under stress.

\subsection{Summary}

Thermal imaging offers an exciting means for imaging humans to extract vital signs in clinical conditions. Understanding the physics and camera parameters is crucial to design the experiments necessary to complete this work. One of the advantages to using thermal imaging is that subjects in the camera's field of view are invariant to light, as the subjects act as the light source. The complexity of the circulatory system is evident when modeling the transport of fluid and heat throughout. Fourier's law implies that heat variations on the skin vary inversely to the distance-i.e. the thickness of the skin/fat layers in the tissue - from the heat source. The environment is responsible for convective sources of cooling which will have the greatest effect when there is the most airflow, i.e. around the air passages such as the nose/mouth. Sweat, or evaporative cooling, can also play a role in generating cooler areas on the skin and may need to be accounted for depending on the application. Most importantly, in areas devoid of hair and fatty tissue, such as the forehead, the primary contributions of heat originate from the minute temperature variations in the blood and core temperatures. 


\section{FLUID FLOW OVERVIEW}

\subsection{Characteristics of the fluids}

Fluid mechanics is the branch of physics that studies fluids (liquids, gases, and plasmas) and the forces on them. It can be divided into fluid statics that study fluids at rest and fluid dynamics that study fluids in motion.

A fluid can be defined as the substance that deforms and flows under the action of a net shear force, no matter how thick or viscous it is the ratio of the shear force to the area on which it acts is known as the shear stress (Massey, Ward Smith et al., 2006). Fluids can be liquids, gases and plasmas. A fixed amount of a liquid has a definite volume which varies only slightly with temperature and pressure. Fluid dynamics can deal with fluid flow from different scopes which are also the common fluid properties, several of these properties will be discussed here:

\section{Molecular structure:}

All substances consist of large numbers of molecules separated by empty space and these molecules have attraction for one another. The different characteristics between liquids, gases, and solid are resulted from the differences between their molecular structures (Massey, Ward-Smith et al., 2006).

\section{DENSITY:}

The basic definition of density of any substance means the ratio of the mass of a given amount of this substance to the volume it occupies .this definition can be applied on liquids, for example if we are talking about water then the density of the water means 
the ratio of the mass of a given amount of the water to the volume it occupies (Massey, Ward-Smith et al., 2006). Another definition called the mean density which is the ratio of the mass of a given amount of a substance to the volume that amount occupies.

\section{Pressure:}

Pressure that a fluid always has is resulted from the innumerable molecular collisions. Any part of the fluid must experience forces exerted on it by adjoining fluid or by adjoining solid boundaries (Massey, Ward-Smith et al., 2006).

\section{Compressible vs. incompressible flow:}

All fluids are compressible to some extent and that depends on the pressure and temperature which affects the density of the fluid .change of pressure applied to a certain amount of substance always produce some change in its volume. The inverse of the compressibility is called the bulk modulus which characterize the degree of compressibility of a substance, often denoted as, $\mathrm{K}$, which is illustrated in (3.1).

$$
K=\frac{\delta p}{\delta \mathrm{V} / \mathrm{V}}
$$

Where $\delta \mathrm{p}$ represents a small increase in pressure applied to the material and $\delta \mathrm{V}$ the corresponding small increase in the original volume V (Massey, Ward-Smith et al., 2006). Although there is a wide variation in compressibility of different substances. As a liquid is compressed its molecules become closer together, so its resistance for further compression increases, that is, $\mathrm{K}$ increases. The bulk modulus of water, for example, roughly doubles as the pressure is raised from $105 \mathrm{~Pa}(1 \mathrm{~atm})$ to $3.5 \times 108 \mathrm{~Pa}(3500 \mathrm{~atm})$. There is also a decrease of $\mathrm{K}$ with increase of temperature, which is illustrated in (3.1). When the change in the temperature and pressure are sufficiently small which leads to 
small change in density, this small change in density can be neglected and in this case the flow can be modeled as an incompressible flow, otherwise it is compressible flow.

\section{Viscosity:}

There will be a resistance to any forces that tend to cause movement for any layer over another for all the fluids. Viscosity is a fluid property which is responsible for that resistance of the fluid layers to move over each other. Motion of layers requires shear forces to be applied, that is, forces parallel to the surfaces over which they act, the resisting forces must be applied on the opposite direction of the shear forces and also parallel to the surface .Under some particular conditions, some fluids offer greater resistance to flow than another, such as treacle and glycerin which cannot be poured rapidly or easily stirred. viscosity is generally of high importance near solid boundaries because of the presence of a thin layer of high strain rate which is known as boundary layer .The fluid immediately adjacent to the boundary must move at the same speed as the boundary, which is called "no-slip" condition in fluid mechanics (Massey, WardSmith et al., 2006).

\section{Inviscid fluid:}

Inviscid fluid can is a hypothetical fluid that has zero viscosity when it moves, which sometimes referred to ideal fluid (Massey, Ward-Smith et al., 2006).

\section{Steady vs. unsteady flow}

Steady flow is the flow in which the various parameters at any point don't change with time. On the other hand, an unsteady flow or non-steady flow is the flow that various parameters change with time. In other words, when all the time derivatives of a flow field are zero, the flow is considered to be a steady flow. In practice, many problems 
may be simplified and studied effectively by assuming that the flow is steady. Such flows are called quasi-steady. By definition, turbulent flows are unsteady (Massey, Ward-Smith et al., 2006).

\section{Laminar Vs. Turbulent flow}

When a fluid flows, it has been categorized into two different kinds, laminar flow which is also called streamline flow and turbulent flow. There are sharp differences between laminar and turbulent flow conditions. At law velocities, a few duct flows exhibit the laminar flow characteristics, where layers of adjacent fluid slide over each other in an ordered manner, exerting shear forces because of the relative movement. Fluid particle paths (streamlines) are straight, with fluid near stationary solid surfaces (pipe wall) moving more slowly than fluid away from solid surfaces. The velocity in the flow direction is constant and steady and does not vary with time. The velocity perpendicular to the flow direction is zero at all times. Compared to turbulent flow, this kind of flow occurs at the lower velocities.in the laminar boundary layers, fluid motion is highly ordered and it is possible to identify streamlines along which particles move. Fluid motion along a streamline is characterized by velocity components in both the $\mathrm{x}$ and $\mathrm{y}$ direction.

(a)

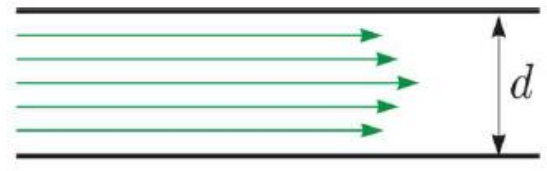

(b)

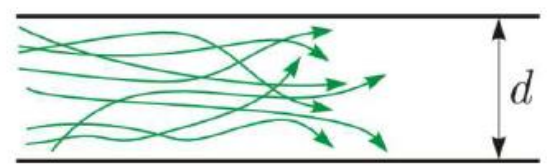

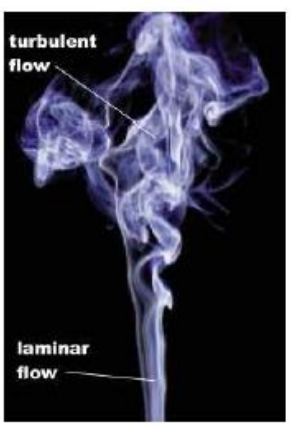

FIG. 3.1 LAMINAR FLOW IS REPRESENTED IN (A) AND TURBULENT FLOW IS REPRESENTED IN (B). RISING SMOKE DEMONSTRATES THE TRANSITION BETWEEN LAMINAR AND TURBULENT FLOW. IMAGE COURTESY: THERMODYNAMICS \& FLUIDS. 
In contrast, in turbulent flow, the paths of fluid particles are no longer straight. If the velocity of a laminar flow is gradually increased there comes a point at which the nature of the flow changes. Particle paths become irregular and chaotic, leading to large scale mixing between adjacent layers. Fluid motion in the turbulent boundary layer is highly irregular and is characterized by velocity fluctuations. Fluid mixing that result from the fluctuations makes turbulent boundary layer thickness larger and boundary layer profiles (velocity, temperature, and concentration) flatter than in laminar flow (Massey, Ward-Smith et al., 2006). The two types of the flow are being illustrated in figure (3.1).

To know the behavior of the boundary layer we calculate a dimensionless number, which called Reynolds number. The Reynolds number represents the ratio of the inertial to the viscous forces within the flow.

The Reynolds number $(\mathrm{Re})$ is illustrated in equation (3.2) as:

$$
R e=\frac{\rho V D}{\mu}=\frac{V D}{v}
$$

Where $\mathrm{V}, \mathrm{D}, \mu, \rho$ and $v$ show the representative velocity, the characteristic length, the dynamic viscosity, the density, and the kinematic viscosity $\left(v=\frac{\mu}{\rho}\right)$ of the fluid, respectively. The term ( $\rho \mathrm{VD}$ is the momentum per unit volume, so the higher it is the more likely there is spare energy in the flow for turbulent behavior. (Potter and Wiggert., 2009).

To get the Reynolds number of a flow in a channel with circular cross section, the characteristic length is conventionally taken as the channel diameter and the 
representative velocity is the mean velocity. The critical Re for pipe geometry is about 2000. Below this, flow is laminar; above it, turbulence tends to start. Usually for fluid flowing through pipes, $(\mathrm{Re})$ is less than 2000 may be considered laminar and if the $(\mathrm{Re})$ is greater than 4000 it may be regarded as turbulent. It can be laminar flow or turbulent flow in the interval between 2000 and 4000, depending upon other factors, such as flow uniformity and pipe roughness (Massey, Ward-Smith et al., 2006).

\section{Womersley number:}

Womersley number $(\alpha)$ is another version of the Reynolds number which is also considered as the pulsatile version of it. It is also a dimensionless number. It is a dimensionless expression of the pulsatile inertia of the flow in relation to viscous effects .the Womersley number $(\alpha)$, can be expressed as illustrated in Eq.(3.3):

$$
\alpha=\mathrm{R}\left(\frac{\omega \rho}{\mu}\right)^{1 / 2}=\mathrm{R}\left(\frac{\omega}{v}\right)^{1 / 2}
$$

Where:

R: a characteristic length scale (radius for a of a pipe),

$\omega$ : angular frequency of the oscillations,

$v$ : kinematic viscosity,

$\rho$ : density,

$\mu$ : dynamic viscosity of the fluid (Gudbjartsson and Patz, 1995). 
Both the Reynolds number and the Womersley number have been used to define the critical values for turbulence. Both of the Reynolds number and Womersley number are dimensionless numbers and being used on the development of turbulence (in-vitro) for physiological realistic pulsatile flow.

\section{Newtonian vs. non-Newtonian fluids}

The fluid said to be a Newtonian fluid if the shear stress of it is directly proportional to the velocity gradient, there are many fluids that considered as Newtonian fluids such as air, water And oil.

In contrast, in the non-Newtonian whenever the relationship between shear stress and strain rate is non-linear. Non-Newtonian fluids usually have a complex molecular composition. Examples of non-Newtonian fluids are liquid plastics and blood (Potter and Wiggert, 2009).

\subsection{Summary}

The ability of quantify fluid and flow properties is helpful to solve many problems in different fields, one of these fields is the medicine field. For example, studying blood flow characteristics and properties helps in finding solutions and early detection for superficial venous disease, blood clots, hemolysis, platelet activation and thrombus formation. 


\section{MEASUREMENT TECHNIQUES FOR FLOW AND VOLUME OF BLOOD}

There are several methods for flow visualization and quantitative velocity measurements; also there are several methods that are used for blood flow and volume measurement.

Measurement of blood flow is very important and it can help to detect many diseases earlier. Measurement of blood flow can be done by several methods and it can be categorized into several classes. The first class can be done by getting the concentration of $\mathrm{O} 2$ and other nutrients in the cell, which is can be difficult in some cases. The difficulties in class one leads the doctors to measure the blood flow and the changes in blood volume which usually correlate with the concentration of the nutrients. If the blood flow is difficult to measure, then the physician may settle for the measurement of the blood pressure which correlates adequately with the blood flow.

Measurement of the blood flow reflects the primary measurement of the concentration of $\mathrm{O} 2$ in the cells. However, the measurement of the blood flow is usually difficult to make and also more invasive than the measurement of the blood pressure.

There are some tools that were used to measure blood flow such as the orifice or turbine flow meter, but these methods were unsuitable because it requires cutting the vessel and can cause formation of clots. These methods have been developed and some of them will be illustrated here: 


\subsection{Measurement techniques of the blood}

\section{The Indicator - Dilution}

The Indicator - Dilution, this method uses continuous infusion. This method finds the flow average over a number of heart beats. To find the concentration $\mathrm{c}$ of an indicator when a given quantity $\mathrm{m}_{0}$ of the indicator is added to a volume, this can be done by applying the equation which is illustrated in (4.1).

$$
c=\frac{m_{0}}{v}
$$

If an additional amount of the quantity is added, then the incremental increase in the concentration is $\Delta \mathrm{c}$ (Donovan and Taylor, 2006). This is illustrated in equation (4.2).

$$
\Delta c=\frac{m}{v}
$$

\section{Fick technique}

This method can be used to measure the cardiac output (blood flow from the heart), several methods for measuring the cardiac output is shown in figure (4.1). There is a difference in the concentration of the $\mathrm{O} 2$ between the blood that is returning to the heart from the upper half of the body and the lower half of the body because the amount of the O2 extracted by the brain is different from that extracted by the other organs. The measurement of the cardiac output can be done using the equation illustrated in (4.3) as follows (Capek and Roy, 1988):

$$
f=\frac{d m / d t}{c_{a}-c_{v}}
$$

Where:

$\mathrm{f}=$ blood flow, liter/min 
$\mathrm{c}_{\mathrm{a}}=$ arterial concentration of $\mathrm{O} 2$ liters/liter

$\mathrm{dm} / \mathrm{dt}=$ consumption of $\mathrm{O} 2$

$\mathrm{c}_{\mathrm{v}}=$ venous concentration of $\mathrm{O} 2$ liters/liter

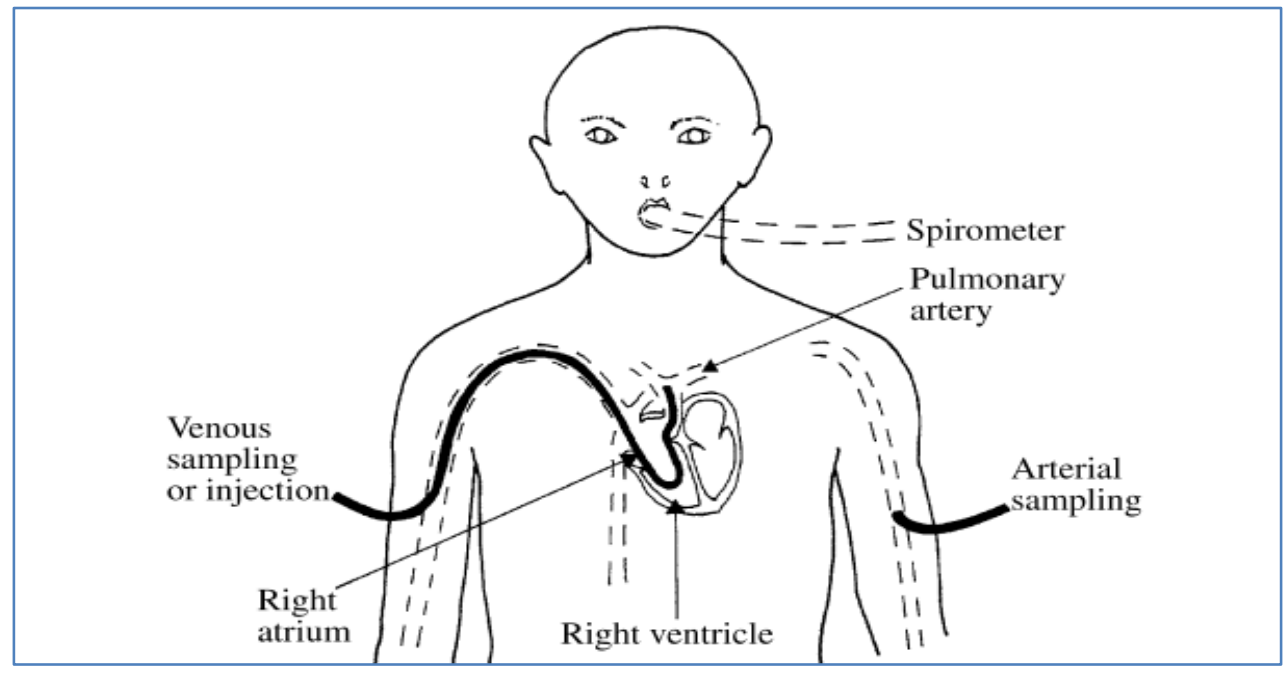

FIG. 4.1 SEVERAL METHODS FOR MEASURING THE CARDIAC OUTPUT .COURTESY, BLOOD FLOW MEASUREMENTS

\section{Dye Dilution method}

This method is used to measure the cardiac output by using a colored dye and Indocyanine green. The Dye is available as a liquid and that is dilated in a substance called isotonic saline and injected directly through a catheter, usually into the pulmonary artery.

\section{THERMODILUTION method}

This is the most common method to measure the cardiac output, this can be done by injecting a bolus of cold saline as an indicator. A special four-lumen catheter is floated through the brachial vein into a place in the pulmonary artery. In this method, the resulting drop in the temperature of the blood is detected by a thermistor located near the catheter tip in the pulmonary artery. 


\section{Electromagnetic Flowmeters method}

In this method, the electromagnetic Flowmeter measures instantaneous flow of blood. This method operates with any conductive liquid, such as blood or saline. The idea of generating the electricity by induction in the electric generator of the car uses copper wires which move through a magnetic field, cutting the lines of magnetic flux and inducing an emf in the wire. This idea has been applied here. A blood flowmeter has been used instead of the copper wire. Using the Faraday's law of induction gives the formula for the induced emf. When the blood flows in the vessel with uniform velocity profile $u$ and passes through a uniform magnetic field $\mathrm{B}$, the induced emf is being calculated as shown in the equation (4.4), where these three components are orthogonal.

$$
\mathrm{e}=\mathrm{BLu}
$$

\section{Laser Doppler blood flowmeter}

In this method a $5 \mathrm{~mW}$ He-Ne laser beams $632.8 \mathrm{~nm}$ light through the fiber optics into the skin (Khaodhiar and Veves, 2006). Moving red blood cells in the skin frequency shift the light and cause spectral broadening. Reflected light is carried by fiber optics to a photodiode. Filtering, weighting, squaring, and dividing are necessary for signal processing [Capillary blood flow has been studied in the skin and many other organs.]

\section{Chamber plethysmography method}

This method measures the changes in the volume of the blood, it is considered an accurate way to measure the changes in the volumes of the blood noninvasively by using the chamber plethysmography. That can be done by timing these volume changes, measurement of the flow can be computed by $\mathrm{f}=\mathrm{dv} / \mathrm{dt}$. A cuff is used to prevent venous blood from leaving the limb. (Seagar et al., 1984). 
Also there are several techniques for measuring and visualization of the velocity of the flow and the blood, these methods are being illustrated here:

\section{Tracer methods}

The most common fluid velocity measurement techniques is the particle tracking. It is used to get the velocity of the fluid at a particular point and time from measurement of the motion of these small particles that is mixed with the fluid. Measurement system of the particle tracking consist of three components, these components are an illumination source, tracking particles and an observation system. Flow velocity could be measured assuming that the particles faithfully follow the streamline of the flow. There are two generic types of tracer methods such as Particle Image Velocimetry (PIV) and Laser Doppler Velocimetry (LDV), (Emirch, 1981).

\section{Particle Image Velocimetry (PIV)}

This method is a noninvasive tracer method for measuring flow velocity in a fluid field. In contrast to single point measurement techniques, PIV can concurrently acquire two-dimensional velocity information across an entire plane making it possible to detect in-plane two-dimensional flow structures with excellent spatial and temporal resolution. This makes it particularly valuable for time-dependent flows. The liquid is seeded with tracer particles which, because of their small size, are assumed to faithfully follow the flow streamlines. The fluid with entrained particles is illuminated usually by a laser light source in any desired plane so that particles are visible. The displacement of the particles is used to calculate speed and direction of the flow (Adrian, 2005).

\section{Two-component PIV (2C-PIV)}


Based on the velocity definition which is the first derivative of the position, this method measures the displacement of the fluid (or particles which faithfully follow the streamline of the flow) over a known time interval to drive the velocity. The displacement of the fluid element is imaged through the light which is scattered by liquid or solid fluorescent particles illuminated by a laser light sheet. Such particles are not usually present in the fluid, the liquid has to be seeded with such tracer particles. These particles should be small enough and have the same density of the fluid to follow the local flow velocity patterns (Brossard, Monnier et al., 2009).

\section{Stereoscopic-PIV (SPIV)}

SPIV is a very well technique to measure all three components (3C) of the velocity vector in the plane of a laser sheet. The principle of this component is that outof-plan component of the velocity vector which is the component perpendicular to a laser light sheet can be measured by adding a second camera to the system, and also arranging both of the cameras at different viewing angle, each camera measure the displacement of the seeding particles perpendicular to its viewing angle. These two different projections of velocity, one from each camera can be combined to reconstruct the $3 \mathrm{C}$ velocity vector. The resulting system is called the Stereoscopic-PIV (SPIV). (Van Doorne and Westerweel, 2007).

\section{Prop methods}

There are several examples of these methods such as Pitot Prope, Propller, Vane anemometer, hot-wire and hot-film anemometers. These methods in contrast to tracer methods are invasive and less sensitive at low fluid velocities (Emirch, 1981).

\section{Doppler based methods}


The idea of the Doppler Effect is based on transmitting an ultrasound beam with a certain frequency and a well-known angle through a liquid at which, the solid particles or the gas bubbles reflect a part of the ultrasound energy. Due to the movement of the particles, a frequency shift is being observed in the reflected beam. This frequency shift corresponds to the velocity of the particles. of the particles. Examples of these methods are Doppler ultrasound (Niederer, 2010), laser Doppler flowmetry (Rajan, Varghese et al., 2009) and optical Doppler tomography (Chen, Milner et al., 1997).

\section{Phase-Contrast Magnetic Resonance Imaging (MRI)}

This method is very prone to motion such that motion artifacts are the most common causes of image degradation. Here, blood and Cerebrospinal fluid (CSF) flows are among the involuntary movements, resulting in a variety of flow effects. Although methods such as "flow compensation" are used to eliminate the flow artifacts, the same concept can be used advantageously to develop non-invasive techniques to image the vascular anatomy and/or to measure the blood velocity. This technique is called Magnetic Resonance Angiography (MRA) and are classified into three major categories: Contrast enhanced angiography (anatomy), Time-of-flight (anatomy and flow velocity), and Phase contrast MR angiography (PC-MRI) (anatomy and flow velocity) (Hornak, 2008). Compared to nuclear medicine and radiographic techniques, MR based flow quantification does not involve use of ionizing radiation. Furthermore, contrast mechanisms independent of contrast agents are available for MRA. Compared to Doppler based methods, on the other hand, MRI can be used to measure the blood velocity using arbitrary image plane orientations without restrictions such as acoustic windows. More importantly, MR based flow quantification techniques can provide all three components 
of the velocity vector, compared to the single component (in the direction of insonification) obtained from Doppler ultrasound.

Phase contrast method relies on the fact that moving spins experience different magnetic field gradients compared to static spins. Consequently, their accumulated phase would be different from static spin. In addition the phase shift is proportional to the product of the flow velocity and the first moment of the magnetic field gradient in the direction of the flow. The velocity field obtained from this method can be used to drive other clinically useful hemodynamic parameters such as wall sheer stress and blood pressure gradient (Nasiraei-Moghaddam, Behrens et al, 2004; Frydrychowicz, Stalder et al., 2009; Harloff, Nussbaumer et al., 2010). PC-MRI has been applied in several clinical scenarios, such as evaluation of aortic coarctation and dissection, valvular heart abnormalities, peripheral arterial diseases and congenital shunt lesions, as well as quantification of cardiac function (Szolar, Sakuma et al., 1996; Srichai, lime r al, 2009).

\subsection{Summary}

Measuring the blood flow rate plays an important role in many medical applications among which is vascular disease diagnosis. Vascular disease is a disorder that occurs in the blood vessels which can lead to improper human blood circulation. Among vascular diseases are arterial disease that affects arteries which carry oxygen-rich blood from the heart to the body organs, and venous disease that affects veins which carry blood back from the organs to the heart to be purified. Regarding the veins, superficial veins which are located near the skin surface can have a clot on it. There are 
some different techniques to diagnose superficial venous disease and one of them is to diagnose it using a thermal image, this method will be discussed in later chapters. 


\section{A NON-INVASIVE METHOD FOR MEASURING BLOOD FLOW RATE IN SUPERFICIAL VEINS FROM A SINGLE THERMAL IMAGE}

Measuring the blood flow rate plays an important role in many medical applications among which is vascular disease diagnosis. Vascular disease is a disorder that occurs in the blood vessels which can lead to improper human blood circulation. Among vascular diseases are arterial disease that affects arteries which carry oxygen-rich blood from the heart to the body organs, and venous disease that affects veins which carry blood back from the organs to the heart to be purified. Regarding the veins, they can be categorized into deep veins which are located deep away from the human skin surface, and superficial veins which are located near the skin surface. This thesis focuses superficial venous disease which can be practically diagnosed using a thermal image.

Superficial veins can be affected by Thrombophlebitis [Bagavathiappan09] that is the development of a blood clot in the vein lowering the blood flow rate in it. And since superficial veins are responsible for transferring heat between the blood and the surrounding environment through the skin, a low blood flow rate in these veins can lead to an improper heat transfer process and improper temperature of the skin in the region of the affected vein. For instance, if it is supposed for warm blood in a certain superficial vein to give out a certain amount of heat, it can lose more amount due to low flow as the blood will flow for a longer time through its surrounding cooler tissues leading to more heat loss which rises the temperature of these tissues. This is clear through thermal 
imaging as the temperature of the skin in an abnormal region appears higher than that in a normal region as illustrated by Bagavathiappan et al. [Bagavathiappan09]. Other related works are presented in [Ratovoson10, Boué07, and Ratovoson11]. In [Ratovoson10], Ratovoson et al. used thermal imaging to study the effect of strong thermal variations on Thermomechanical behavior of the skin which can be applied for body burns. They extended their work in [Ratovoson11] by presenting a numerical model to simulate the average blood velocity in veins under thermal stress in which metabolism and blood perfusion effects are negligible. Boué et al. [Boué07] presented a thermal model for the forearm and estimated the blood flow by using a heating source to stimulate a skin.

In this chapter, The work of [Bagavathiappan09] is being interpreted in a quantitative manner in which a single thermal image of superficial veins can not only detect that abnormality but also can measure the blood flow rate through veins, pressure drop along the veins and the amount of heat lost due to the shear stress exerted by the viscosity of the blood. Throughout this work, blood assumed to be a Newtonian [Santos08] incompressible fluid whose flow is laminar. Blood vessels will be modeled as cylindrical tubes in which the flowing blood loses heat by convection to the surroundings. Moreover, time-average velocity is used to deal with pulsatile flow as steady state flow [Bourantas11]. This experiments will contain two parts: 1) validating this concept by building a setup that simulates superficial veins, and 2) vivo measurement validation for a human subject.

\subsubsection{LAMINAR FLOW INSIDE A TUBE}

In Laminar flow, the fluid streamlines are parallel [Post10] and orderly slide over 
each other while in turbulent flow, irregularity occurs to the flow pattern as adjacent layers mix with each other. In order to determine the type of the flow inside a cylindrical tube, Reynold's number $\mathrm{R}_{\mathrm{e}}$ [Menon04] should be calculated as illustrated in equation (5.1):

$$
\mathrm{R}_{\mathrm{e}}=\frac{\rho \mathrm{u}_{\mathrm{avg}} \mathrm{D}}{\mu},
$$

Where, $\mu$ and $\rho$ are the fluid dynamic viscosity and density respectively, and $u_{\text {avg }}$ is the average fluid velocity inside the tube whose inner diameter is, D. If $R_{e}<2000$, the flow is laminar and if $R_{e}>4000$ the flow is turbulent. For values between 2000 and 4000, the flow can be either laminar or turbulent (critical flow [Menon04]). In this thesis, the work will be restricted only to the case of laminar flow i.e. we will deal only with flow with $R_{e}<2000$. This is why thin tubes are being used as lowering $D$ means lowering $R_{e}$.

\subsubsection{FLOW RATE USING CONVECTION HEAT TRANSFER}

Forced convection [Incropera90] refers to the presence of heat transfer along with a fluid flow inside a solid (e.g. a tube) under the effect of an external influence (e.g. a pump) when the fluid and the solid are at different temperatures. For a tube, the heat transfer occurs from the fluid to the tube wall if the temperature of the fluid is higher than that of the tube wall and occurs from the tube wall to the fluid if the temperature of the tube wall is higher. There will be consideration for the later case in deriving the equations in this section. However, the obtained equations will be also valid for the other case. Although a fluid can be either a liquid or a gas, this thesis deals with liquids only. 


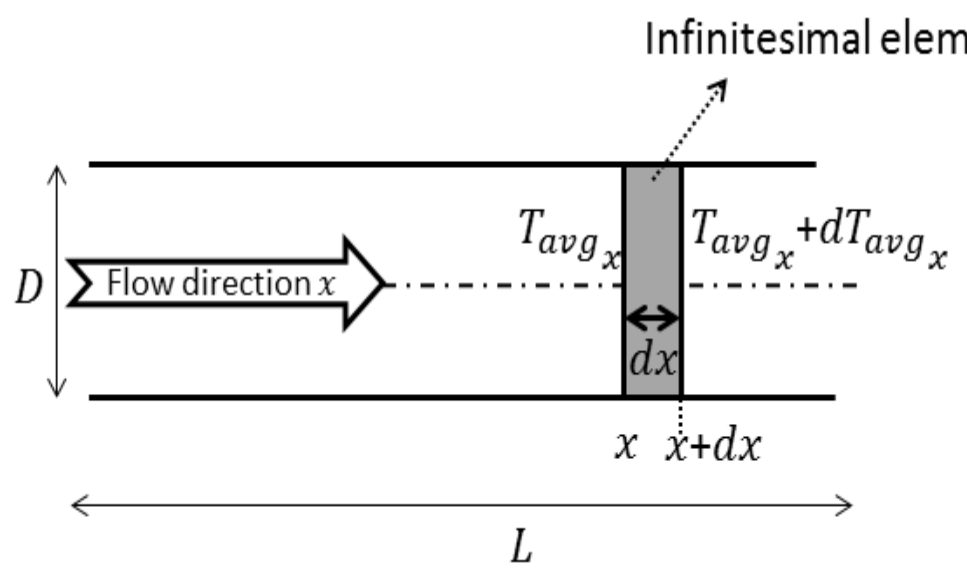

Figure 5.1, Cylindrical tube in which fluid average temperature changes by $\mathrm{dT}_{\mathrm{avg}_{\mathrm{x}}}$ along an infinitesimal element of length $\mathrm{dx}$.

The convection heat transfer is composed of two mechanisms [Incropera90]: heat transfer due to diffusion and heat transfer by the bulk motion of the liquid taking into account that the contribution in heat transfer due to bulk motion of the liquid is dominant over diffusion. Consider the cylindrical tube portion shown in Fig. (5.1) in which D, and L are the inner diameter, and length respectively. For an infinitesimal cylindrical element of length $\mathrm{dx}$, the rate of convection heat transfer per unit area of the surface of that element is known as the convection heat flux and is given by Newton's law of cooling [Incropera90] as illustrated in equation (5.2):

$$
\mathrm{q}_{\text {conv }}{ }^{\prime \prime}=\mathrm{h}_{\mathrm{c}}\left(\mathrm{T}_{\mathrm{w}}-\mathrm{T}_{\mathrm{avg}_{\mathrm{x}}}\right)
$$

Where, $\mathrm{h}_{\mathrm{c}}$ is the local convection heat transfer coefficient and $\mathrm{T}_{\mathrm{avg}}$ is the liquid temperature averaged over the tube inner radius at an arbitrary point x. Applying the law 
of conservation of energy, the rates of energy entering and exiting the mentioned infinitesimal volume should be equal. Thus the convection heat transfer rate should equal the sum of the rate of increase in the thermal energy of the liquid and the rate of the work done by the flow through the mentioned infinitesimal volume and hence the rate of convection heat transfer between $\mathrm{x}$ and $\mathrm{x}+\mathrm{dx}$ is given by equation (5.3):

$$
\mathrm{dq}_{\text {conv }}=\dot{\mathrm{m}} \mathrm{c}_{\mathrm{p}} \mathrm{dT}_{\mathrm{avg}_{\mathrm{x}}}
$$

Where, $c_{p}$ is the liquid specific heat at constant pressure and $\dot{m}$ is the mass flow rate which is related to the volumetric flow rate $\dot{V}$ given by equation (5.4):

$$
\dot{\mathrm{m}}=\rho \dot{\mathrm{V}} .
$$

And from the definition mentioned above of the convection heat flux and having the surface area of the infinitesimal element $\pi \mathrm{Ddx}, \mathrm{dq}_{\mathrm{conv}}$ can be written also as illustrated in equation (5.5):

$$
\mathrm{dq}_{\mathrm{conv}}=\mathrm{q}_{\mathrm{conv}}{ }^{\prime \prime} \pi \mathrm{Ddx} \text {. }
$$

Equating Eq. (5.3) and Eq. (5.5), gives equation illustrated as (5.6):

$$
\frac{\mathrm{dT}_{\mathrm{avg}}}{\mathrm{dx}}=\frac{\mathrm{q}_{\mathrm{conv}}{ }^{\prime \prime} \pi \mathrm{D}}{\dot{\mathrm{mc}}_{\mathrm{p}}}
$$

Integrating Eq. (5.6) from 0 to $\mathrm{x}$ while assuming constant heat flux at the tube wall gives $\mathrm{T}_{\mathrm{avg}_{\mathrm{x}}}$ varying linearly with $\mathrm{x}$ as illustrated in equation (5.7):

$$
T_{a v g_{x}}=T_{a v g_{0}}+\frac{q_{c o n v}{ }^{\prime \prime} \pi D}{\dot{m} c_{p}} x
$$

Where, $\mathrm{T}_{\mathrm{avg}_{0}}$ is the average temperature of the liquid at the entrance of the tube portion. And for laminar flow [Incropera90], $\mathrm{h}_{\mathrm{c}}=4.36 \frac{\mathrm{k}}{\mathrm{D}}$ assuming fully developed thermal conditions, where, $\mathrm{k}$ is the thermal conductivity of the liquid. Thus substituting 
for the values of $q_{\text {conv }}{ }^{\prime \prime}$ from Eq. (5.2) and $\dot{m}$ from Eq. (5.4), Eq. (5.7) is reduced to the equation illustrated in (5.8):

$$
\mathrm{T}_{\mathrm{avg}_{\mathrm{X}}}=\mathrm{T}_{\mathrm{avg}_{0}}+\frac{4.36 \mathrm{k}\left(\mathrm{T}_{\mathrm{w}}-\mathrm{T}_{\mathrm{avg}_{\mathrm{x}}}\right) \pi}{\rho \dot{\mathrm{V}} \mathrm{c}_{\mathrm{p}}} \mathrm{x}
$$

Substituting for $\mathrm{x}$ by $\mathrm{L}$ in the previous equation and arranging it gives the liquid volumetric flow rate $\dot{V}$ as illustrated in equation (5.9):

$$
\dot{\mathrm{V}}=\frac{4.36 \mathrm{k} \pi \mathrm{L}\left(\mathrm{T}_{\mathrm{w}}-\mathrm{T}_{\mathrm{avg}}\right)}{\rho \mathrm{c}_{\mathrm{p}}\left(\mathrm{T}_{\mathrm{avg}_{\mathrm{L}}}-\mathrm{T}_{\mathrm{avg}_{0}}\right)}
$$

\subsubsection{PRESSURE DROP AND POWER LOSS DUE TO FRICTION}

Consider a portion of length $\mathrm{L}$ of the cylindrical tube as shown in Fig. (5.2). Assuming the motion of the liquid inside the tube to be frictionless i.e. neglecting the viscosity effect, Bernoulli's principle [Rose04] implies that the sum of kinetic energy and potential energy along the stream tube remains constant, and hence, the sum of the static pressure, dynamic pressure, and gravitational pressure remains constant which is illustrated in equation (5.10):

$$
\mathrm{p}+\frac{1}{2} \rho u^{2}+\rho \mathrm{gz}=\text { constant }
$$

Where, $\mathrm{p}$ is the liquid static pressure, $\frac{1}{2} \rho \mathrm{u}^{2}$ is the dynamic pressure, and $\rho g z$ is the gravitational pressure with $\mathrm{u}, \mathrm{g}$ and $\mathrm{z}$ being the liquid velocity, gravitational acceleration and height with respect to a given reference level respectively. Considering point 1 and point 2 at the beginning and end of the tube portion respectively, Eq. (5.10) becomes the equation illustrated in (5.11):

$$
\mathrm{p}_{1}+\frac{1}{2} \rho \mathrm{u}_{1}^{2}+\rho g \mathrm{z}_{1}=\mathrm{p}_{2}+\frac{1}{2} \rho \mathrm{u}_{2}^{2}+\rho g \mathrm{z}_{2}
$$


Practically, the effect of liquid viscosity should be taken into account, as liquid viscosity is a measure of its resistance to shape change brought by shear stresses between liquid layers and between liquid and tube walls.

The shear stress between the liquid and the tube walls causes friction that is dissipated in the form of heat. That shear stress acts along the inner surface of the tube portion whose surface area is $\pi \mathrm{DL}$ and exerts a force in a direction opposing the flow. In order to overcome that force, a pressure drop $\Delta \mathrm{p}$ occurs inside the tube portion [Rose 04 , Warhaft98] which modifies Eq. (5.11) to the equation illustrated in (5.12):

$$
\mathrm{p}_{1}+\frac{1}{2} \rho \mathrm{u}_{1}^{2}+\rho \mathrm{gz}_{1}=\mathrm{p}_{2}+\frac{1}{2} \rho \mathrm{u}_{2}^{2}+\rho \mathrm{gz}_{2}+\Delta \mathrm{p} .
$$

The pressure drop $\Delta p$ can be interpreted into a force acting on the tube inner cross sectional area $\frac{\pi D^{2}}{4}$. This force is equal in magnitude to the force exerted by the shear stress [Post10]. The velocity profile across the tube for laminar flow is parabolic with maximum value at the centerline of the tube and zero values at the tube walls [Warhaft98] given by equation illustrated as (5.13):

$$
u=-\frac{D^{2}}{16 \mu} \frac{d p}{d x}\left(1-\left(\frac{2 r}{D}\right)^{2}\right),
$$

Where, dp is the pressure drop occurring along an infinitesimal cylindrical element of length $d x$ and height $r$, and coaxial with the centerline of the tube with the positive $\mathrm{x}$ direction being the direction of the flow as shown in Fig. (5.2). 


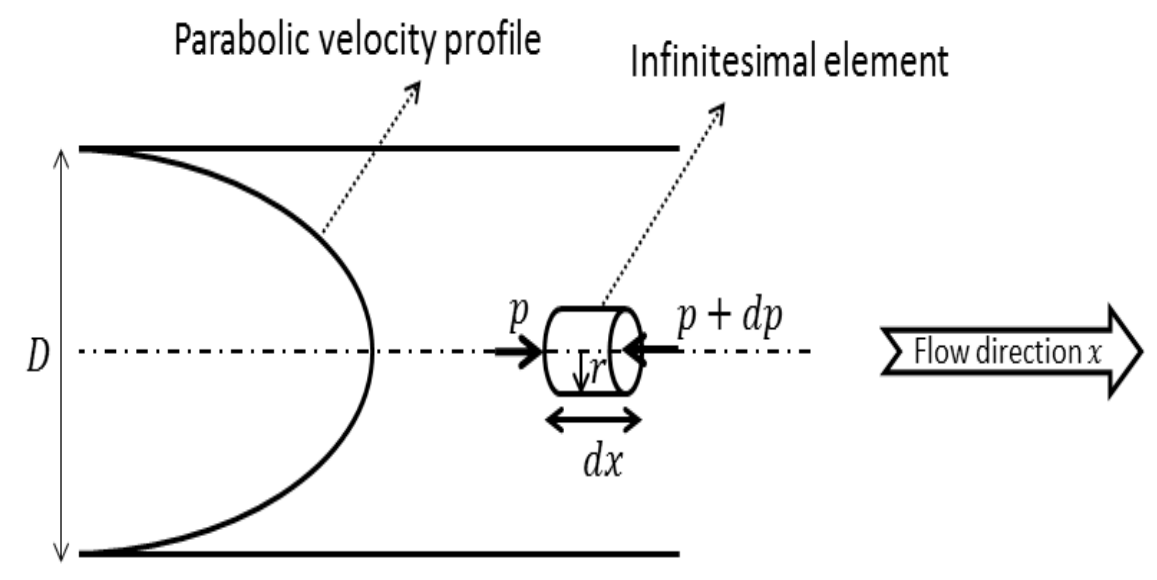

Figure 5.2, parabolic velocity profile for a cylindrical tube with laminar flow

Since the velocity is not uniform across the tube, integration should be used when calculating the volumetric flow rate $\dot{V}$. Consider dealing with a thin shell of thickness $\mathrm{dr}$ at a distance $r$ form the tube centerline. The shell cross sectional area $d A=2 \pi r d r$ and the volumetric flow rate through that shell $d \dot{V}$ is given by equation illustrated as (5.14):

$$
d \dot{V}=u d A .
$$

Substituting Eq. (5.13) into Eq. (5.14) and integrating $r$ across the tube from 0 to $\frac{D}{2}$ gives the equation illustrated as (5.15):

$$
\dot{V}=-\frac{\pi}{128 \mu} \frac{d p}{d x} D^{4} .
$$

Assuming uniform flow during the tube portion under consideration, $\frac{\mathrm{dp}}{\mathrm{dx}}$ is a constant [Warhaft98] and thus can be replaced by $-\frac{\Delta p}{L}$ and hence Eq. (5.15) is simplified to the equation illustrated as (5.16):

$$
\Delta \mathrm{p}=\frac{128 \mu \mathrm{L}}{\pi \mathrm{D}^{4}} \dot{\mathrm{V}}
$$


From the first law of thermodynamics (conservation of energy) [Post10], the power loss $\mathrm{P}_{\text {loss }}$ due to a pressure drop $\Delta \mathrm{p}$ is given by equation illustrated as (5.17):

$$
\mathrm{P}_{\text {loss }}=\dot{\mathrm{V}} \Delta \mathrm{p},
$$

Substituting for $\Delta \mathrm{p}$ from Eq. (5.16) gives equation illustrated as (5.18):

$$
\mathrm{P}_{\text {loss }}=\frac{128 \mu \mathrm{L}}{\pi \mathrm{D}^{4}} \dot{\mathrm{V}}^{2} .
$$

From Eq. (5.16) and Eq. (5.18), it is clear that succeeding to measure the

volumetric flow rate $\dot{V}$ leads directly to the knowledge of $\Delta \mathrm{p}$ and $\mathrm{P}_{\text {loss }}$. The liquid properties as the viscosity, density, thermal conductivity, and specific heat capacity are temperature dependent but can be practically found at the reference temperature [Incropera90] and then assumed to be constant along the tube. The reference temperature is found by averaging the mean temperatures of the liquid at the inlet and the outlet of the tube.

\subsection{Blood vessel convective heat transfer}

In this thesis, the focus is on superficial veins which can be practically seen in a thermal image. While blood flows in the veins, heat is exchanged between the blood and the surrounding tissues [Haemmerich03]. Penne [Pennes48] in 1948 showed that blood flow acts as a warming agent for the superficial veins while studying the forearm. $\mathrm{He}$ assumed that there are two main heat sources in the tissues, which are heat transfer from blood to the tissues and heat generated in the tissue by metabolism. The later occurs at a low rate near the surface of the forearm. He stated that the rate of heat transfer from the blood to the tissue at a certain location is proportional to the difference between the blood temperature and the tissue temperature. 
The tissues surrounding blood veins can be modeled as solid [Ratovoson10]. Thus assuming a superficial blood vein to be a very thin cylindrical shell surrounded by these solid tissues, and assuming blood to be a Newtonian [Santos08] incompressible laminarly flowing fluid for which time-average velocity is used to deal with pulsatile flow -due to heart beating- as steady state flow [Bourantas11], the heat transfer between the flowing blood and the surrounding tissues can be formulated as a case of forced convection heat transfer in a cylindrical [Leeuwen97] tube under laminar flow. Thus, the equations presented in the previous section can be applied directly to this case. Analyzing Eq. (5.9), it is clear that the difference between the inlet and outlet blood temperatures of a certain vein is inversely proportional to volumetric blood flow rate. This quantitatively clarifies the reason for the improper heat transfer and improper temperature of the skin in the region of a superficial vein that is affected by thrombophlebitis [Bagavathiappan09], and hence increases the drop in the temperature of the blood exiting the vein with respective to its temperature at the inlet. In other words, superficial veins are responsible for transferring heat between the blood and the surrounding environment through the skin, so if it is supposed for warm blood in a certain superficial vein to give out a certain amount of heat, it can lose more amount due to low flow as the blood will flow for a longer time through its surrounding cooler tissues leading to more heat loss which rises the temperature of these tissues and decreases the temperature of the blood.

In this work, there is a validation for this concept by observing the effect of varying the flow rate of a liquid flowing in a cylindrical tube on the difference in the temperatures of the liquid entering and exiting that tube. These temperatures will be fed into Eq. (5.9) to get an estimate of the volumetric flow rate and compare it with ground 
truth. The estimated volumetric flow rate can then be fed into Eq. (5.16) and Eq. (5.18) to get an estimate for the pressure drop and power lost by the viscosity respectively. Another part of our experiments is to image the superficial veins in the forearm of a living human subject and see the effect of lowering the blood flow rate on the difference in the temperatures of the blood entering and exiting a superficial vein. The temperature in our experiments will be estimated using thermal imaging which is briefly discussed the next section.

\subsection{THERMAL imaging basics}

The concept of thermal imaging arose from studying the phenomenon of Blackbody radiation [Robert02]. A blackbody at a temperature $\mathrm{T}$ above $0 \mathrm{~K}$ continuously absorbs and then diffusely reemits photons (light quanta) of all possible wavelengths $\lambda(\lambda$ ranges from 0 to $\infty$ ). It was found that the number of photons emitted per unit wavelength at a certain wavelength is dependent on T. This is clear in Planck's law which gives the radiation spectral intensity of a blackbody at temperature $\mathrm{T}$ as illustrated in equation (5.19) [Robert02]:

$$
\mathrm{B}_{\lambda}(\mathrm{T})=\frac{2 \mathrm{hc} \mathrm{c}^{2}}{\lambda^{5}} \frac{1}{\mathrm{e}^{\frac{\mathrm{hc}}{\mathrm{KT} \lambda}}-1}
$$

Where, $\mathrm{h}=6.625 \times 10^{-34} \mathrm{~J} \mathrm{~s}$ (Planck's constant), $\mathrm{K}=1.37 \times 10^{-23} \mathrm{~J} \mathrm{~K}^{-1}$ (Boltzmann's constant) and $\mathrm{C}=3 \times 10^{8} \mathrm{~m} \mathrm{~s}^{-1}$ (light speed). If the peak of Eq. (5.19) occurs at $\lambda_{\max }$, the product of $\lambda_{\max }$ and $\mathrm{T}$ is a constant given by Wien displacement law [Lianxi09] as illustrated in equation (5.20):

$$
\lambda_{\max } \mathrm{T}=2.897 \times 10^{-3} \mathrm{~m} \mathrm{~K}
$$


As a result, the dominant emitted wavelength is in the visible light range for an extremely high temperature body (thousands of kelvins). As the body temperature gets lower, the dominant wavelength moves towards the infrared regions (NIR, SWIR, MWIR, LWIR). Integrating Eq. (5.19) over a hemisphere for $0<\lambda<\infty$, gives the power radiated per unit area of the emitting surface at temperature $\mathrm{T}$ as illustrated in equation (5.21) (Stefan-Boltzmann law [Robert02]):

$$
R(T)=\sigma T^{4},
$$

Where, $\sigma=5.67 \times 10^{-8} \mathrm{~W} \mathrm{~m}^{-2} \mathrm{~K}^{-4}$ is the Stefan-Boltzman constant.

For a non-blackbody, beside the phenomenon of temperature based emission of photons, there is also reflection of photons incident from an external visible light source. Since the emitted photons carry information about the body temperature, succeeding in separating that portion of photons from the reflected portion gives the temperature of the body. Fortunately, at low temperature (few hundreds of kelvins), the dominant wavelength of the emitted photons lies in the infrared region, thus they are band separated from the reflected visible photons. Based on this, thermal infrared cameras can give the temperature of a body. An important surface property related to thermal imaging is the emissivity [Siegel81] which indicates how well a real object emits radiation compared to a blackbody at the same temperature and wavelength. Emissivity depends on the wavelength and the direction of emission. Taking into account averaged emissivity $\varepsilon$ over all wavelengths and all directions, Eq. (5.21) is modified to equation illustrated as (5.22):

$$
\mathrm{R}(\mathrm{T})=\varepsilon \sigma \mathrm{T}^{4},
$$


Where, the averaged emissivity $\varepsilon$ takes values from 0 to 1 . In the above discussion, we were assuming dealing with wavelengths from 0 to $\infty$. Practically, the used thermal camera wavelength band should be taken into consideration.

\subsection{Experimental results}

In this experiment, the blood flow will be estimated using thermal images captured by a FLIR LWIR thermal camera operating in the 7.5-13 $\mu \mathrm{m}$ wavelength range with a resolution of $640 \times 480$ pixels. The thermal sensitivity of the camera is $50 \mathrm{mK}$. The IR lens used with the camera has a $41.3 \mathrm{~mm}$ focal lens and a 17 micron pixel detector. The thermal camera is mounted vertically at a distance 1 meter from a horizontal tube (or vein).For this setup,

1 pixel in the thermal image represents $396 \mu \mathrm{m} \times 396 \mu \mathrm{m}$. This spatial calibration was done by taking a thermal image for a hot rod with known length and at a known distance from the lens.

In the first part of the experiment, two cylindrical tubes will be used to simulate superficial veins. One of them has a throttle that causes the liquid flow to be slower simulating a vein with stenosis while the other one has normal flow representing a healthy vein. The tubes will contain water flowing horizontally using a pump that is controlled by a generator to supply either continuous flow or pulsatile flow. The water temperature at the pump is kept at $37^{\circ} \mathrm{C}$ while the container (where the tubes are mounted horizontally) contains ice at $0{ }^{\circ} \mathrm{C}$ as shown in Fig. (5.3).

The temperature is being measured at the inlet and the outlet of the tubes which will show a drop due to the convection heat transfer from the hot water in the tubes to the 
ice in the container.

This temperature drop is then used in Eq. (5.9) -which is repeated here for convenience- to calculate the volumetric flow rate in the two tubes as illustrated in equation (5.23):

$$
\dot{\mathrm{V}}=\frac{4.36 \mathrm{k} \pi \mathrm{L}\left(\mathrm{T}_{\mathrm{w}}-\mathrm{T}_{\mathrm{avg}}\right)}{\rho c_{\mathrm{p}}\left(\mathrm{T}_{\mathrm{avg}}-\mathrm{T}_{\mathrm{avg}_{0}}\right)}
$$

The following values were used for the constants in the equation: $\mathrm{k}=0.626 \frac{\mathrm{J}}{\mathrm{K} \mathrm{m} \mathrm{s}}$, $\rho=994.1 \frac{\mathrm{Kg}}{\mathrm{m}^{3}}, \mathrm{c}_{\mathrm{p}}=4178 \frac{\mathrm{J}}{\mathrm{Kg} \mathrm{K}}$ and $\mathrm{L}=0.24 \mathrm{~m}$. Hence the resulting volumetric flow rate should be in $\mathrm{m}^{3} / \mathrm{s}$ which is equal to $10^{6} \mathrm{~mL} / \mathrm{s}$. Fig. (5.4) shows the temperature profile along the cross sections of the tubes at the inputs and outputs where it is clear that the tube with the throttle reduced flow rate of the water leading to more heat loss. This leads to a temperature drop of $1{ }^{\circ} \mathrm{C}$ between the input and the output of the throttled tube compared to a temperature drop of $0.45^{\circ} \mathrm{C}$ in the regular tube as shown in Fig. (5.4). For both cases, the difference between the wall temperature and the average temperature is $4.3{ }^{\circ} \mathrm{C}$, hence the flow can be calculated using Eq. (5.9) to be 2.1 and $4.7 \mathrm{~mL} / \mathrm{s}$ in the tubes with and without the throttle respectively. The ground truth for these flow rates were measured to be 1.8 and $5.0 \mathrm{~mL} / \mathrm{s}$ respectively by dividing the volume of water dispensed in each case by the time of the experiment. The target of this part of the experiment was just to validate the theory behind our approach in a setup where the ground truth can be easily measured. This experiment was repeated several times and similar results were obtained. These results show that the proposed method is reliable for estimating the flow. 


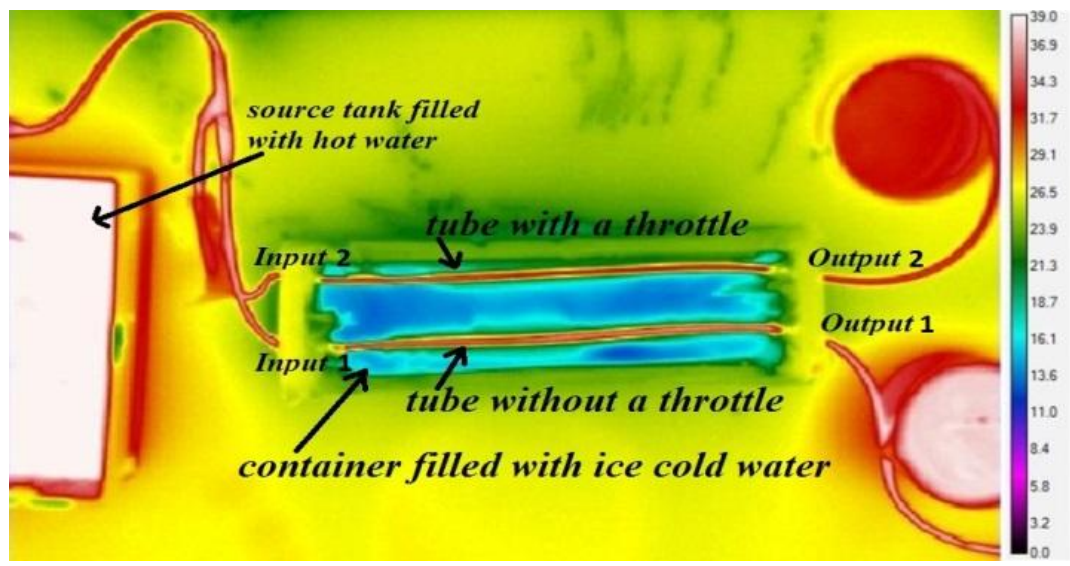

FIGURE 5.3, A THERMAL IMAGE SHOWING THE FIRST PART OF THE EXPERIMENT WHERE THE UPPER TUBE HAS A THROTTLE WHILE THE LOWER TUBE IS REGULAR.

Feeding the calculated $\dot{V}$ values into Eq (5.16) and Eq. (5.18), with a diameter $\mathrm{D}=0.3 \mathrm{~cm}$ and viscosity $\mu=710 \times 10^{-6} \frac{\mathrm{N} . \mathrm{s}}{\mathrm{m}^{2}}$, leads directly to $\Delta \mathrm{p}$ and $\mathrm{P}_{\text {loss }}$
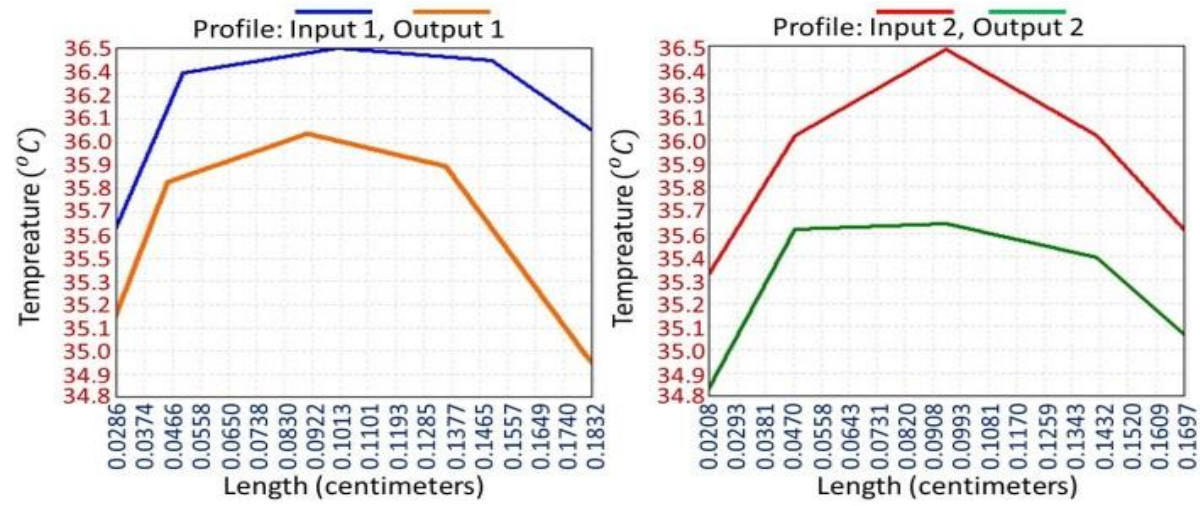

Figure 5.4, Temperature profiles along the cross sections of the tubes at the inputs and outputs for the tube with a throttle on right and without a throttle on left.

In the second part of the experiment, the same ideas will be applied of the first part to a human forearm. An ice pack is being used on the forearm so that the blood flowing in the veins will have a temperature drop due to the convection heat transfer. a thermal image is being captured for the forearm after putting an ice pack on it as shown in Fig. (5.5). The temperature of the vein before and after the cold part will be used to calculate the blood flow rate using Eq. (5.9) as happened in the first part of the experiment. 
For validation, estimation for the blood flow needs to be done in a subject for a normal vein and compare it with the same subject and the same vein if it has a stenosis. To simulate that, a thermal image is being captured for a subject and then we put a thin cuff around the forearm to lower blood flow and capture another thermal image as shown in Fig. (5.5). By comparing the results, it will give an estimation and a feeling of how the stenosis will reduce the blood flow. The following values were used for the blood at $37^{\circ} \mathrm{C}, \mathrm{k}=0.549 \frac{\mathrm{J}}{\mathrm{K} \mathrm{m} \mathrm{s}}, \rho=1060 \frac{\mathrm{Kg}}{\mathrm{m}^{3}}$, and $\mathrm{c}_{\mathrm{p}}=3820 \frac{\mathrm{J}}{\mathrm{Kg} \mathrm{K}}$. L from the input to the output was measured form the thermal image to be $0.053 \mathrm{~m}$.
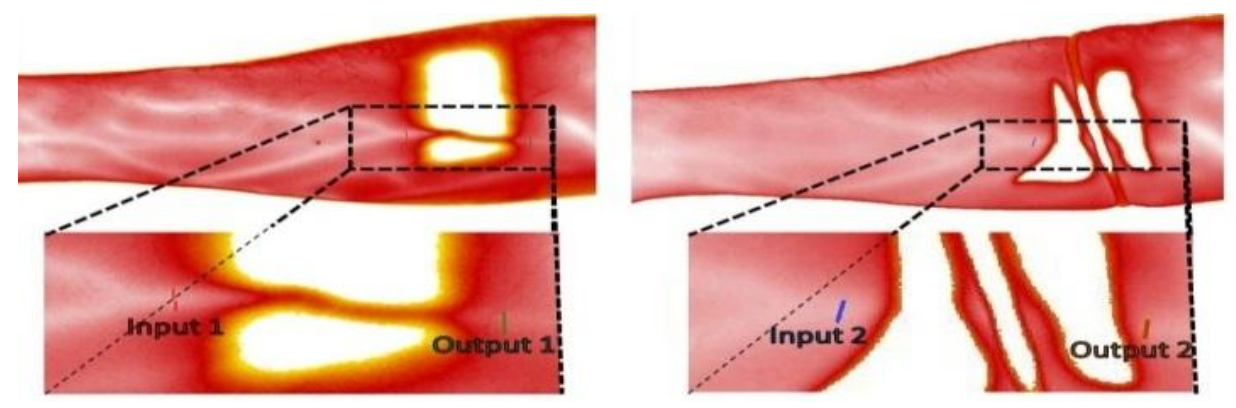

Figure 5.5, Thermal images showing the right forearm after putting an ice pack over a vein with a cuff around the vein in the right image.

The input and the output locations should be on the vein before and after the ice pack location respectively. These locations do not have to be in the same physical spots for different images taking into consideration that the distance between them is the length L which is part of Eq. (5.9). In Fig. (5.5), it is taken in the way such that the distance L is equal in both images but that was not necessary. Fig. (5.6) shows a temperature drop of $0.7^{\circ} \mathrm{C}$ between the input and the output of the healthy vein compared to a temperature drop of $0.95{ }^{\circ} \mathrm{C}$ in the throttled vein. For both cases, the difference between the wall temperature and the average temperature is $0.42{ }^{\circ} \mathrm{C}$, leading to a blood flow rate of 0.06 and $0.04 \mathrm{~mL} / \mathrm{s}$ for the regular and stenotic case respectively. 

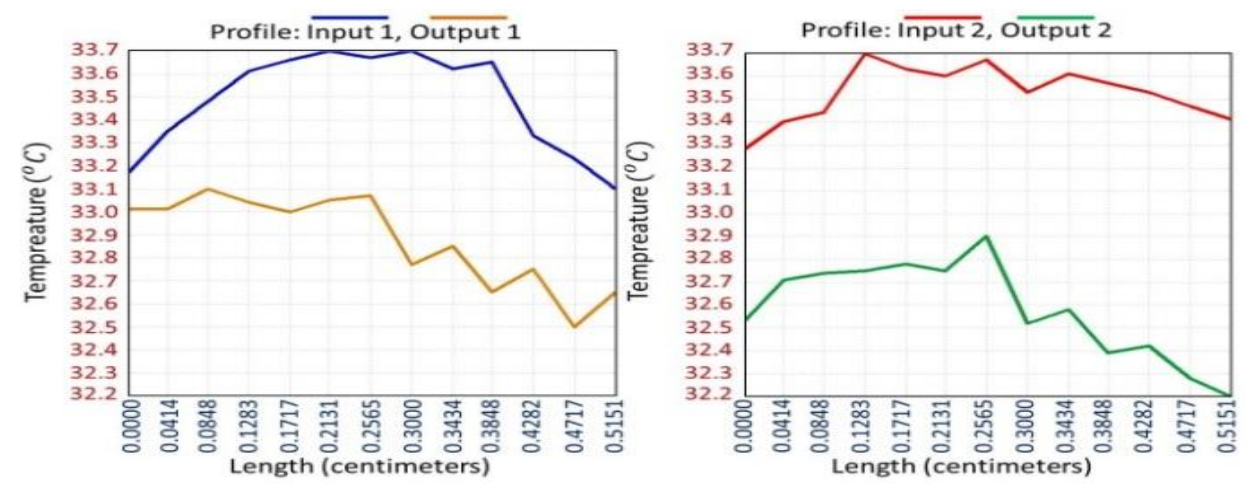

FIGURE 5.6, TEMPERATURE PROFILES ALONG THE CROSS SECTIONS OF A VEIN AT THE INPUTS AND OUTPUTS FOR THE TUBE WITH A CUFF ON RIGHT AND WITHOUT A CUFF ON LEFT.

\subsection{Summary}

Measurement of blood flow is usually more difficult to make and more invasive than measurement of blood pressure or of the ECG. There are several methods for the blood flow to individual organs and it involves the use of flow probes or sensors. There are common available systems for the measurement of in vivo blood flow which can be divided into two categories like: ultrasonic and electromagnetic. Another way of measuring the blood flow is presented here which measure the volumetric flow rate of a liquid inside a thin tube using thermal camera, applying this idea on a superficial veins can be helpful to diagnose superficial venous disease and earlier detection of them. 


\section{CONCLUSIONS AND FUTURE WORK}

The measurement of blood flow rate is important to identify, treat, and evaluate life-threatening conditions of patients. Thermal imaging is an efficient way for tracking the blood flow and detecting problems with it. This methodology now makes the task of monitoring vital signs possible without the need for sensor contact on the subject. This process is aided when the physics and physiology of the systems are used to remove additional noise elements from the biological system and environment using biological skin-heat transfer modeling. Physical and computer modeling have revealed it is possible to conduct controlled experiments to evaluate thermal blood-flow-based experiments on demand, without the need for human subjects to test.

In this thesis, the volumetric flow rate of a liquid inside a thin tube was estimated non-invasively using a single thermal image. This technique makes use of the difference in the liquid temperatures at the inlet and the outlet of the tube caused by convection heat transfer. That temperature difference was shown analytically and experimentally to be dependent on the volumetric flow rate and thus can be used to give a good estimate for

the flow rate. A tested for this method is done with the superficial veins of a human subject forearm. The experiment was done once for the case of regular blood flow and once for stenotic blood flow. Here there is a proposed work to use this technique to noninvasively diagnose superficial venous disease that significantly affects the blood flow in 
the veins. Although this research was done on normal subjects, there is an intention to test it in the future with patients having superficial venous disease. 


\section{REFERENCES}

[Mahmoud et al., 13] A. Mahmoud, A. EL-Barkouky, H. Farag, J. Graham, A. Farag. A Non-invasive Method for Measuring Blood Flow Rate in Superficial Veins from a Single Thermal Image, 2013.

[ Bagavathiappan09] S. Bagavathiappan, T. Saravanan, J. Philip, T. Jayakumar, B. Raj, R. Karunanithi,T. Panicker, M. Korath, and K. Jagadeesan. Infrared thermal imaging for detection of peripheral vascular disorders. J Med Phys, 34(1):43-47, 2009.

[ Ratovoson10] D. Ratovoson, F. Jourdan, and V. Huon. A study of heat distribution in human skin: use of Infrared Thermography. 14th International Conference on Experimental Mechanics, 2010.

[Boué07] C. Boué, F. Cassagne, C. Massoud, and D. Fournier. Thermal imaging of a vein of the forearm: Analysis and thermal modeling. Infrared Physics \& Technology, 51(1): 13-20, 2007.

[Ratovoson11] D. Ratovoson, V. Huon, V. Costalat, and F. Jourdan. Combined model of human skin - Heat transfer in the vein and tissue: experimental and numerical study. Quantitative InfraRed Thermography Journal, 8(2): 165-186, 2011.

[Santos08] I. Santos, D. Haemmerich, C. Pinheiro, and A. Rocha. Effect of variable heat transfer coefficient on tissue temperature next to large vessel during radiofrequency tumor ablation. BioMedical Engineering Online, 11:7-21, 2008

[Bourantas11] G. Bourantas, E. Skouras, V. Loukopoulos, V. Burganos, and G. Nikiforidis. Two-phase blood flow modeling and mass transport in the human aorta. 10th International Workshop on Biomedical Engineering, 1-4, 2011.

[Post10] S Post. Applied and Computational Fluid Mechanics. Jones \& Bartlett Learning, 2010.

[Menon04] E. Menon. Liquid Pipeline Hydraulics. CRC Press, 2004. 
[Incropera90] F. Incropera, and D. DeWitt. Introduction To Heat Transfer. second edition, Wiley, 1990.

[Rose04] C. Rose. An Introduction to the Environmental Physics of Soil, Water and Watersheds. Cambridge University Press, Cambridge, UK, 2004.

[Warhaft98] Z. Warhaft. An Introduction to Thermal-Fluid Engineering: The Engine and the Atmosphere. Cambridge University Press, Cambridge, UK, 1998.

[Haemmerich03] D. Haemmerich, A. Wright, D. Mahvi, F. Lee, and J Webster. Hepatic bipolar radiofrequency ablation creates coagulation zones close to blood vessels: A finite element study. Med Biol Eng Comput, 41:317-323, 2003.

[Pennes48] H. Pennes. Analysis of tissue and arterial blood temperatures in resting human forearm. Journal of Applied Physiology, 1:93-122, 1948.

[Leeuwen97] V. Leeuwen, A. Kotte, J. DeBree, J. VanderKoijk, J. Crezee, and J. Lagendijk. Accuracy of geometrical modelling of heat transfer from tissue to blood vessels. Phys. Med Biol., 42:1451-1460, 1997.

[Robert02] J. Robert Mahan. Radiation Heat Transfer, A Statistical Approach. WILEY, 2002.

[Lianxi09] Lianxi Ma, Junjun Yang and Jiacai Nie. Two forms of Wien's displacement law. Lat. Am. J. Phys. Educ. 3(3):566-568, 2009.

[Siegel81] R. Siegel, and J. Howell. Thermal Radiation Heat Transfer. Hemisphere Pub. Corp., 1981.

[A-Hassan86] Abul-Hassan HS, Ascher GD, Acland RD (1986) Surgical anatomy and blood supply of the fascial layers of the temporal region. Plast Reconstr Surg 77(1):7-28

[Atamaz06] Y. Atamaz and F. Govsa. Anatomy of the superficial temporal artery and its branches: its importance for surgery. Surg. Radiol. Anat. 28(3.1):248-253, 2006. 
[Balasubram77] T.A. Balasubramaniam and H.F. Bowman. Thermal conductivity and thermal diffusivity of biomaterials: A simultaneous measurement technique. J. Biomech. Engr. 99, 148-154, 1977.

[Barber05] Barber, T. et al (2005). Infrared Absorption Spectroscopy. Environmental Instrumentation and Analysis Handbook. R. Down and J. Lehr. New Jersey: John Wiley \& Sons, Inc. pgs 87-117. (C) 2005.

[Bourlai10] T. Bourlai, P. Buddharaju, I. Pavlidis, and Barbara Bass, "Methodological advances on pulse measurement through functional imaging", in Computational Surgery and Dual Training, Advances in Pattern Recognition. pgs: 101-121, Springer, 2010.

[Buddharaju07] P. Buddharaju, et al. Physiology-Based Face Recognition in the Thermal Infrared Spectrum. TPAMI. 29(3.2):613-26, 2007.

[Campbel197] Campbell, C. Arterial waveforms - monitoring changes in configuration. Heart \& Lung. May-June 1997.

[Chan05] K. Chan, Y. Sun, and S. Krishnan, "Characteristic wave detection in ECG signal using morphological transform," BNC Cardiovascular Disorders. Vol. 5, No. 28, Sept. 2005

[Chato90] J.C. Chato. Fundamentals of bioheat transfer. In Thermal Dosimetry and Treatment Planning, M Gautherie, ed., Springer-Verlag, New York, 1990, p. 51.

[Chekmenev06] S. Chekmenev, A. Farag, and E. Essock. Multi-resolution Approach for NonContact Measurements of Arterial Pulse using Thermal Imaging. Proc. CVPR. 2006.

[Chekmenev07] S. Chekmenev, A. Farag, and E. Essock. Thermal Imaging of the Superficial Temporal Artery: An Arterial Pulse Recovery Model. CVPR. 2007.

[Cohen77] M. Cohen. Measurement of the thermal properties of human skin. A review. The Journal of Investigative Dermatology. The Williams and Wilkins Co. 69(3):333338. (1) 1977

[Cooper71] T.E. Cooper and G.J. Trezek. Correlation of thermal properties of some human tissue with water content. Aerospace Med.42, 24-27, 1971. 
[Cotterill09] S. Cotterill. "The Cardiovascular System." CancerIndex University of Newcastle upon Tyne, 31 Aug. 2000. Web. $11 \quad$ Aug. 2009. <http://www.cancerindeorg/medterm/medtm8.htm>.

[Diastole10] “diastole.” Merriam-Webster's Medical Dictionary. Merriam-Webster, Inc. 10. Oct. 10. http://www.merriam-webster.com/medical/diastole.

[Daubechies94] Daubechies, I. (1994). Ten Lectures on Wavelets. Montpelier, VT: Capital City Press. ㄷ 1994.

[Douchet08] A. Doucet and A. Johansen. A Tutorial on Particle Filtering and Smoothing: Fifteen years later. Tech. Dec. 2008.

[Dowdall03] J. Dowdall, I. Pavlidis, and G. Bebis. "Face Detection in the Near-IR Spectrum." Image and Vision Computing. 21(2003): 565-578.

[Dowdall07] J. Dowdall, I. Pavlidis, and P. Tsiamyrtzis. "Coalition Tracking." CVIU 106(2007): 205-19. 2007.

[Ducharme91] M. Ducharme and P. Tikuisis. "In vivo thermal conductivity of the human forearm tissues." Department of Physiology, University of Toronto, Toronto, Ontario M5S $1 \mathrm{Al}$; and Defense and Civil Institute of Environmental Medicine, North York, Ontario M3M 3B9, Canada

[Ekman97] In Ekman, P., \& Rosenberg, E.L. (Eds.) What the Face Reveals: Basic and Applied Studies of Spontaneous Expression using the Facial Action Coding System (FACS). Pp.1-125. New York: Oxford University Press.

[Electrophys08] Electrophysics (2008). White Paper: Understanding thermal Camera Image Quality. Electrophysics Resource Center: Thermography. (C) 2008.

[Gault10] T. Gault, N. Blumenthal, A. Farag and Tom Starr. "Extraction of the Superficial Facial Vasculature, Vital Signs Waveforms and Rates Using Thermal Imaging," Proc. IEEE OTCBVS'10. San Francisco, CA. 13 June 2010.

[Gault11] T. Gault, E. Mostafa, A. Farag, and A. Farag. "Less is More: Cropping to Improve Facial Recognition with Thermal Images." International Conference on Multimedia and Technology (ICMT’11). Hangzhou China. July 2011. 
[Gault12] T. Gault and A. Farag. "Computationally Light Forehead Segmentation from Thermal Images." International Conference on Image Processing (ICIP'12). Orlando, FL. October 2012.

[Garbey04] M. Garbey, A. Merla, and I. Pavlidis. Estimation of blood flow speed and vessel location from thermal video. CVPR, 1(2004): 356-363, 2004.

[Gonzalez02] R. Gonzalez and R. Woods, "Digital Image Processing, 2nd ed.” pp. 91-94. Upper Saddle River, NJ: Prentice Hall. (C) 2002.

[Gunapala06] Gunapala, S. et al. (2006). Towards dualband megapixel QWIP focal plane arrays. Infrared Phys. Techn. (C) 2006. doi:10.1016/j.infrared.2006.10.005.

[Halliday01] Halliday, D., R. Resnick, and J. Walker (2001). Fundamentals of Physics, 6th ed. New York. Jon Wiley \& Sons, Inc. pgs 426-428, 443-445. (C) 2001

[Hamamatsu04] Hamamatsu (2004). Technical information SD-12: Characteristics and use of infrared detectors. Hamamatsu Photonics K.K., Solid State Division. Nov. 2004.

[Hammoud09] R. Hammoud (Ed). Augmented Vision Perception in Infrared. New York, NY: Springer. Pgs. 87-112. 2009. ISBN: 978-1-84800-276-0

[Hatfield51] H.S. Hatfield and L.G.C. Pugh (1951). Thermal Conductivity of Human Fat and Muscle. Nature. 4282:919-919. 28 June 1951.

[Houdas82] Y. Houdas, E.F.J. Ring, Human Body Temperature: Its Measurement and Regulation, Plenum Press, New York, 1982

[Infrared01] Infrared Detectors. (2001). Updated 22 May 2001. Accessed 6 July 2009. <http://www.electro-optical.com/bb_rad/detector.htm>. (C) 2000.

[Infratec09] InfraTec (2009). Basics. InfraTec - Your specialist for Thermography and Infrared $\quad$ Research. $\quad$ Accessed 29 June 2009. <http://www.infratec.de/indephp?id=59>. (C) 2009.

[Jackway96] Jackway, P. and M. Deriche (1996). Scale-Space Properties of the Multiscale Morphological Dilation-Erosion. IEEE TPAMI. 18(1); 38-51. Jan 1996.pdf alias

[Kadambe99] S. Kadambe, R. Murray, and G.F. Boudreau-Bartels, "Wavelet Transform-Based QRS Complex Detector,” IEEE Trans. Biomed. Engr. 46(7):838-848, Jul. 1999 
[Kakuta02] Kakuta, N. et al. (2002). Human Thermal Models for Evaluating Infrared Images. IEEE Engineering in Medicine and Biology. Dec. 2002

[Kass88] M. Kass, A. Witkin, and D. Terzopoulos. "Snakes: Active Contour Models." IJCV'88. pgs: 321-331.

[Kenner04] F.Kenner, F. "FingerPrint Demo". Mathworks website. http://www.mathworks.com/matlabcentral/fx_files/16728/1/content/FingerPrint/ht ml/fingerprint.html. Accessed Oct. 2004

[Koehler02] B.-U. Köhler, C. Hennig, and R. Orglmeister. "The principles of software QRS detection,” IEEE Eng. Med. Biol. Mag., vol. 21, pp. 42-57, Jan./Feb. 2002.

[Koenderink84] J. Koenderink. (1984). The Structure of Images. Biological Cybernetics. 50(5): 363-370. 1984.

[Kong05] S. Kong et al. (2004). Recent advances in visual and infrared face recognition-a review. Computer Vision and Image Understanding. 97(2005): 103-135. 2004

[Lindeberg94] Lindeberg, T. (1994). Scale-Space Theory in Computer Vision. Dordrecht, The Netherlands: Kluwer Academic Publishers. (c) 1994.

[Lindeberg98] T. Lindeberg. Feature Detection with Automatic Scale Selection. Int. J. Comput. Vision. 30(2): 79-116, 1998.

[Love80] T.J. Love, Thermography as an indicator of blood perfusion, in: R.K. Jain, P.M. Gullino (Eds.), Annals of the New York Academy of Sciences, vol. 335, New York Academy of Sciences, New York, 1980, pp. 429-437.

[Mallat89] S. Mallat. A theory for multiresolution signal decom-position: The wavelet representation. IEEE Trans. Pattern Anal. Machine Intell., 11(7):674-693, 1989.

[Maras09] Maras. C (2009). Cooled versus uncooled - thermal imaging cameras for longrange surveillance. Security News - Source Security.com. Accessed 25 June 2009. <http://www.sourcesecurity.com/news/articles/co-2752-ga.2246.html>.

[NDT08] Non-Destructive Testing (NDT) Education Resource Center (2008). Introduction to Thermal Testing. Updated 25 September 2008. Accessed 23 June 2009. $<$ http://www.ndt- 
ed.org/EducationResources/CommunityCollege/Other\%20Methods/IRT/IR_index. htm>.

[Milnor93] W. Milnor. "Cardiovascular physiology” NY: Oxford UP, 1990.

[Park02] M. Park, C-W. Park, and M. Park. "Algorithm for detecting human faces based on convex-hull." Optics Express. 10(6):274-279. 25 March 2002.

[Patel11] B. Patel and A. Meyers. Forehead Anatomy. Medscape Reference. 27 June 2011. Accessed 10 Aug. 2011. http://emedicine.medscape.com/article/834862

[Penne48] H.H. Pennes, Analysis of tissue and arterial blood temperatures in the resting human forearm, J. Appl. Physiol. 1 (1948) 93-122.

[Perona90] Perona, P. and J. Malik (1990). Scale-Space and Edge Detection using Anisotropic Diffusion. IEEE TPAMI. 12(7); 629-639. July 1990

[Ramakirsh97] A. Ramakrishnan and S. Saha (1997). ECG Coding by Wavelet-Based Linear Prediction. IEEE Trans. Biomed. Engr. 44(12): 1253-1261. Dec. 1997

[Renaud05] O. Renaud, J-L. Starck and F. Murtagh, "Wavelet-Based Combined Signal Filtering and Prediction. IEEE Trans. On Systems, Man, and Cybernetics - Part B: Cybernetics, 35(6): 1241-1251. Dec. 2005.

[Rogalski02] Rogalski, A. and K. Chrzanowski (2002). Infrared devices and techniques. OptoElectronics Rev. 10(2): 111-136. 2002.

[Rogalski06a]Rogalski, A. (2006). Competitive technology of third generation infrared photon detectors. Opto-Electronics Rev. 14(4): 87-101. 2006.

[Rogalski06b]Rogalski, A. (2006). Third generation infrared detectors. Proc. Of the Symposium on Photonics Technologies for 7th Framework Prog. Wroclaw. 12-14 October 2006.

[Sepsis11] "sepsis." Merriam-Webster Online Dictionary. 201. Merriam-Webster Online. 31 Jan. 2011.

http://www.merriam-webster.com/dictionary/sepsis

[Socolinsky04]A. Socolinsky and A. Selinger. Thermal face recognition in an operational scenario. In CVPR (2), pp 1012-1019, 2004. 
[Sostmann95] Sostmann, H. and P. Metz (1995). Fundamentals of Theometry, Part VIII: Radiation Thermometry and Calibration. Isotech Journal of Thermometry. Vol. 6, No. 2. () 1995.

[Steigerwald06] Steigerwald, B. (2006). Inexpensive Detector Sees the Invisible, In Color. Accessed 6 July 2009. <http://www.physorg.com/news67701347.html>.

[Steketee73] J. Steketee. Spectral Emissivity of Skin and Pericardium. Phys. Med. Biol., 18(3.2):686-94, 1973

[Sun05] N. Sun, M. Garbey, A. Merla, and I. Pavlidis. Imaging the cardiovascular pulse. Proc. CVPR. 2005.

[Sun06] N. Sun and I. Pavlidis. Counting Heartbeats at a Distance. Conf Proc IEEE Eng Med Biol. Soc. 2006;1:228-31

[Systole10] “systole.” Merriam-Webster's Medical Dictionary. Merriam-Webster, Inc. 10. Oct. 10. http://www.merriam-webster.com/medical/sysstole.

[Tipler03] Tipler, P. and R. Llewellyn (2003). Modern Physics, 4th Ed. New York: W. H. Freeman and Company. pgs 132-141. (C) 2003.

[Togawa89] Togawa, T. (1989). Non-contact skin emissivity: measurement from reflectance using step change in ambient radiation temperature. Clin. Phys. Physiol. Meas. Vol. 10 No. 10. pgs 39-48. (C) 1989.

[Valens09] C. Valens. A Really Friendly Guide To Wavelets. Web. 23 Aug. 2009. <http://pagesperso-orange.fr/polyvalens/clemens/wavelets/wavelets.html>.

[Valvano87] J.W. Valvano, and B Chitsabesan. Thermal conductivity and diffusivity of arterial wall and atherosclerotic plaque. Lasers Life Sci., 1, 219-229, 1987.

[Weeks02] Weeks, M. and M. Bayoumi (2003). Discrete Wavelet Transform: Architectures, Design and Performance Issues. Journal of VLSI Signal Processing. 35:155-178. 2003.

[Weeks07] Weeks, M. (2007). Digital Signal Processing Using MATLAB and Wavelets. Hingham, MA: Infinity Science Press. (C) 2007. 
[Wu08] S. Wu, W. Lin, and S. Xie. Skin-heat transfer Model of Facial Thermograms and its Application in Face Recognition. Pattern Recognition 41(2008): 2718-729.

[Wu12] H.-Y. Wu et al. Eulerian Video Magnification for Revealing Subtle Changes in the World. SIGGRAPH 2012.

[Wong03] Wong, K. (2003). Intermediate heat transfer. CRC. pgs 283-284. C 2003.

[Yang03] S. Yang and I. Verbauwhede. A Secure Fingerprint Matching Technique. WBMA. Nov. 2003

[Yoon07] H-S. Yoon, J-W. Choi and J-I.Youn. "Method of assessing involved facial areas: rule of fours." British Journal of Dermatology 158:1022-1028. 17 Nov. 2007.

[Zhili04] Zhili, W. "Fingerprint Recognition.” Department of Computer Science. BS Thesis. Hong Kong Baptist University. Sept. 2004. http://www.comp.hkbu.edu.hk/ vincent/thesis/thesis908.pdf. Accessed Oct. 2004.

[Zhou08] Y. Zhou, P. Tsiamyrztis, I. Pavlidis. "A Probabilistic Template Update Method for Tracking Facial Tissue in Thermal Infrared.” IEEE 5th Intl. Conf. AVSS'08. pgs: 99-106. Dec. 2008.

[Zhu08] Z. Zhu, P. Tsiamyrztis, I. Pavlidis. "The Segmentation of the Supra orbital Vessels in Thermal Imagery.” IEEE 5th Intl. Conf. AVSS’08. pgs: 237-244. Dec. 2008. 


$\begin{array}{cl}\text { APPENDIX I. MATHEMATICAL NOMENCLATURE } \\ \alpha & \text { Absorptivity } \\ \varepsilon & \text { Emissivity } \\ q & \text { Heat transfer } \\ H & \text { Heat flux } \\ T & \text { Temperature }(\mathrm{K}, \text { unless otherwise specified) } \\ \sigma & \text { o }=5.6703 \times 10^{-8}, \text { Stefan-Boltzmann constant } \\ P(T) & \text { Radiated power per unit area }\left[\mathrm{W} / \mathrm{m}^{2}\right] \\ f & \text { Frequency } \\ f(t) & \text { Arbitrary Signal } \\ \lambda & \text { Wavelength } \\ I(x, y) & \text { Image intensity at pixel location }(\mathrm{x}, \mathrm{y}) \\ \omega & \text { Blood-perfusion data } \\ \phi & \text { Scaling function } \\ \Psi, \psi & \text { Wavelet function } \\ s & \text { Wavelet scale factor } \\ \tau & \text { Wavelet translation factor } \\ W & \text { Wavelet coefficients for } f(t) \\ \end{array}$




\section{APPENDIX II. ACRONYMNS}

\begin{tabular}{|c|c|}
\hline ANOVA & Analysis of variance \\
\hline $\mathrm{A} / \mathrm{D}$ & Analog to Digital \\
\hline BPM & Beats per minute \\
\hline CVIP & Computer Vision \& Image Processing \\
\hline CWT & Continuous wavelet transform \\
\hline DAQ & Data Acquisition \\
\hline $\mathrm{DC}$ & Direct current \\
\hline DWT & Discrete wavelet transform \\
\hline ECG/EKG & Electrocardiogram \\
\hline FPA & Focal plane array \\
\hline fps & frames per second \\
\hline IR & Infrared \\
\hline L/MWIR & Long/mid wave IR \\
\hline MCT & Mercury, cadmium, tellenium ( $\mathrm{HgCdTe})$ \\
\hline MRA & Multi-resolution analysis \\
\hline MRTD & Minimum resolvable temperature difference \\
\hline MWIR & Mid wave IR \\
\hline NEDT & Noise equivalent difference temperature \\
\hline QWIP & Quantum well IR photodetector \\
\hline ROI & Region of interest \\
\hline
\end{tabular}




$\begin{array}{ll}\text { ROM } & \text { Region of measurement } \\ \text { RPPA } & \text { Radiated power per unit area } \\ \text { RMS } & \text { Root mean squared } \\ \text { ROIC } & \text { Readout integrated circuit } \\ \text { SCA } & \text { Sensor chip assembly } \\ \text { SHT } & \text { Skin-heat transfer } \\ \text { SNR } & \text { Signal-to-noise ratio } \\ \text { SO } & \text { Supra orbital artery } \\ \text { STA } & \text { Superficial temporal artery } \\ \text { TMP } & \text { Thermal minutia point } \\ \text { WFT } & \text { Windowed Fourier transform }\end{array}$




\section{CURRICULUM VITAE}

\section{Heba E Farag}

University of Louisville

Electrical and Computer Engineering Department

Cell phone:502-298-0730

Email: heahme01@cardmail.louisville.edu

Education

University of Louisville 2012-present

Louisville, Kentucky

Electrical and Computer Engineering Department

Completing MS degree (anticipated Dec. 2013), Overall GPA of (3.5)

\section{Higher Technological Institute 2011}

Tenth Of Ramadan City (Main Campus), Ash Sharqiyah, Egypt

BS in Electrical Engineering, Overall grade of "Very Good," graduated with Honours

Graduation Project: Software Defined Radio (LTE platform)

\section{$\underline{\text { Research and Work Experience }}$}

Graduate Research Assistant, ECE Department Summer 2012-present

Engineering Analysis for Colon Medical Research 
Thermal imaging research

Computer Vision and Image Processing Laboratory (University of Louisville)

American Printing House for the Blind (Full time intern student)

\section{Training Courses}

Telephone network (2008)

CCNA (Cisco Certified Network Associate) (2009)

MCITP (Microsoft Certified IT Professional) (2010)

GSM, GPRS, UMTS, LTE for mobile communication (2011)

\section{Computer Skills}

Programming Languages: MATLAB, C\#, Java

Mathematical Software Tools: MATLAB, SIMULINK, Maple, Mathcad, Spice.

Operating Systems: Windows

\section{$\underline{\text { Research Interests }}$}

Medical Applications of Engineering

Machine Learning

Probability random variable and stochastic processes

Publication and conferences

"A Non-invasive Method for Measuring Blood Flow Rate in Superficial Veins from a Single Thermal Image", 9th IEEE Workshop on Perception Beyond the Visible Spectrum (PBVS) In conjunction with CVPR, 2013. 


\section{Honors and Awards}

Theobald Scholarship Award - 2013, University Of Louisville 